\title{
The Effects of Varying the Interval from Follicular Wave Emergence to Progestin Withdrawal on Follicular Dynamics and the Synchrony of Estrus in Beef Cattle
}

\author{
Matthew Douglas Utt
}

Thesis submitted to the Faculty of the Virginia Polytechnic Institute and State University in partial fulfillment of the requirements for the degree of

Master of Science

in

Animal and Poultry Sciences

(Physiology of Reproduction)

W. E. Beal, Chairmain

M. J. Estienne

R. L. Nebel

R. G. Saacke

June 7, 2002

Blacksburg, Virginia

Key Words: Estradiol, Estrus synchronization, Follicle, GnRH, Progestin 
The Effects of Varying the Interval from Follicular Wave Emergence to Progestin Withdrawal on Follicular Dynamics and the Synchrony of Estrus in Beef Cattle

Matthew D. Utt

\section{(ABSTRACT)}

The objective of this experiment was to examine the effects of varying the interval from follicular wave emergence to progestin removal on follicular dynamics and the synchrony of estrus. The experimental design was a $2 \times 2 \times 2$ factorial with $\mathrm{GnRH}$ or estradiol-17 beta $\left(\mathrm{E}_{2}\right)+$ progesterone $\left(\mathrm{P}_{4}\right)$, controlled internal drug-releasing device (CIDR) treatment duration, and PG or saline treatment as main effects. Cycling, Angus cows $(n=49)$, on d 6 to 8 of the estrous cycle, were randomly assigned to receive a CIDR treatment for 7 or $9 \mathrm{~d}$. Approximately half of the cows from each CIDR group received either $\mathrm{GnRH}(100 \mathrm{mcg})$ or $\mathrm{E}_{2}+\mathrm{P}_{4}\left(1 \mathrm{mg} \mathrm{E} 2+100 \mathrm{mg} \mathrm{P}_{4}\right)$ at CIDR insertion. Cows in $\mathrm{GnRH}$ or $\mathrm{E}_{2}+\mathrm{P}_{4}$ groups were further divided into those that received PG (37.5 mg) or saline at CIDR insertion. All cows received PG $(25 \mathrm{mg}) 1 \mathrm{~d}$ prior to CIDR removal. The interval from follicular wave emergence to CIDR removal was longer for cows treated with GnRH (6.6 d) or a CIDR for $9 \mathrm{~d}(6.5 \mathrm{~d})$ compared to those treated with $\mathrm{E}_{2}+\mathrm{P}_{4}(4.7 \mathrm{~d})$ or a 7-d CIDR (4.8 d) (P < 0.05). Cows treated with PG or GnRH at CIDR insertion or a 9-d CIDR had a larger dominant follicle (DF) at CIDR removal than those treated with saline, $\mathrm{E}_{2}+\mathrm{P}_{4}$, or a 7-d CIDR. $(\mathrm{P}<0.07)$. Altering the interval from wave emergence to progestin removal created differences in size of the DF at CIDR removal but did not affect the synchrony of estrus.

Key Words: Estradiol, Estrus synchronization, Follicle, GnRH, Progestin 


\section{Acknowledgements}

There is not one person that I could dedicate this entire work to. The experiences and knowledge I have gained during the course of this Master of Science program have been a combination of the efforts and support but not limited to the following people:

Dr. Bill Beal, who gave me a working knowledge of the estrous cycle of the cow, has not only been a great advisor and mentor, but a friend too. Despite long hours at the farm and the demands he placed on Dean and I, he was always there to help.

Dr. Dick Saacke, who also served as both a mentor and friend, has always had an open door to talk about reproductive physiology or life. The encouragement and support he has given me during my academic career here at Virginia Tech have been invaluable.

Dr. Ray Nebel, whose support and encouragement have been invaluable. I don't know what else to say. He is one of a kind. I have enjoyed his input, advice, and just stopping by to talk.

Dr. Mark Estienne, who thankfully agreed to serve as my long-distance committee member. He has added to a great team of people I have worked with on my committee.

Mr. Lee Johnson, who knows everything about anything, helped with everything from computer problems to hormone assays. I don't know what else to say about Lee, but lab technicians do not come any better.

Mr. Henry Dickerson, has been a great help with the real "work" of my project at the farm. I have had a great time working with him for the past two years. His company always made working at the farm enjoyable.

Mr. Dean Jousan, has been the calm one of the crew. His easy-going attitude has helped balance out some of my more intense moments. He was always willing to lend a hand to help or an ear to listen.

The Physiology Graduate Students, it's been fun! I could not have found a better group to associate with. Thanks for all the support and good times.

Mr. Larry Kuehn, for help with the statistical analysis of data for this experiment. Thanks for keeping an open door to all my questions and concerns.

Miss Heidi Baitis, for spending late nights at the farm and putting up with my frustrations while I was learning the techniques of ultrasonography. Her assistance and encouragement were well appreciated. 
Finally, my family and friends who have supported and encouraged me with everything I have done and accomplished during the last six years here at Virginia Tech.

I would like to acknowledge the following companies for assistance with my thesis project:

DDX Inc., for donating the use of the HeatWatch system used in this project.

Merial, for donating all of the Cystorelin used in this project.

Pharmacia-UpJohn, for donating all of the Lutalyse used in this project. 


\section{Table of Contents}

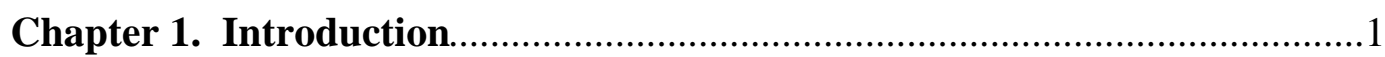

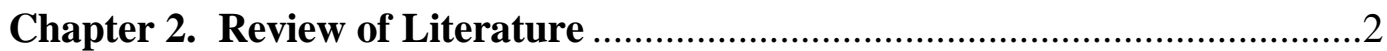

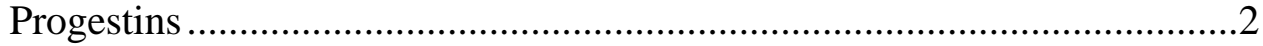

Types of Progestins ...................................................................2

Length of Progestin Treatment and Resulting Fertility....................3

Lowered Fertility Associated with Progestin Treatment.................9

Follicular Events During the Bovine Estrous Cycle .................................10

The Persistent Follicle Revisited................................................................13

Controlling Follicle Emergence ............................................................17

Gonadotropin-Releasing Hormone .........................................17

Estradiol...........................................................................19

Chatper 3. Rationale and Experimental Objectives.................................21

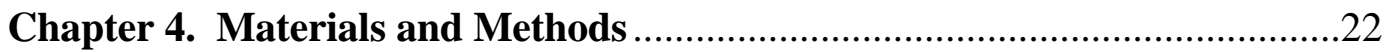

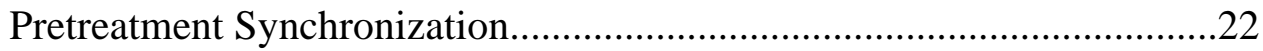

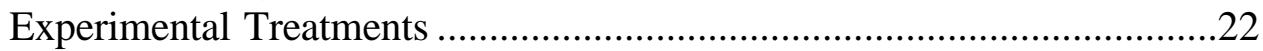

Ultrasound Examinations ..............................................................24

Blood Collection and Progesterone RIA ..............................................24

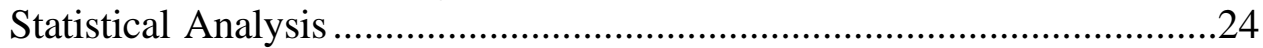

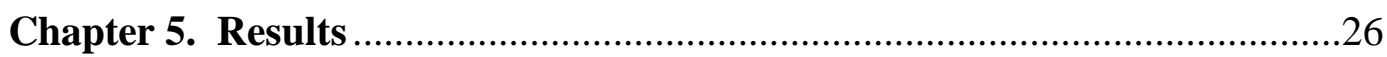

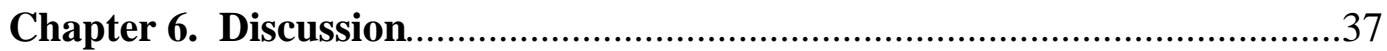

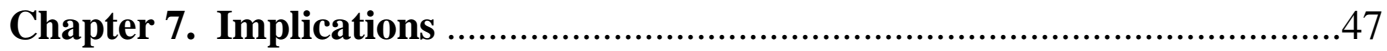

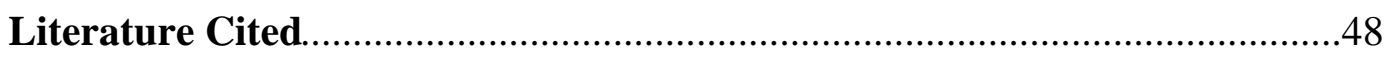

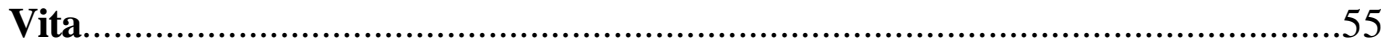




\section{List of Tables}

$\underline{\text { Table }} \quad \underline{\text { Page }}$

2.1 The effect of treatment with varying levels of exogenous progesterone on dynamics of the ovulatory follicle.

Adapted from Sirois and Fortune (1990)

2.2 Time to follicular wave emergence following treatment with estradiol-17 beta and progesterone, GnRH, or follicle ablation. Adapted from Martinez et al. (1997)......

5.1 The main effects of estradiol-17 beta and progesterone or $\mathrm{GnRH}$, 7- or 9-d CIDR treatment, or PG or saline treatment on characteristics of the dominant follicle

6.1 The effect of the duration of dominance of the ovulatory follicle on fertility in heifers. Adapted from Austin et al. (1999) 


\section{List of Figures}

$\underline{\text { Figure }}$

$\underline{\text { Page }}$

2.1 Synchrony of estrus and pregnancy rate following heifers treated with a norethandrolone implant for a duration of 9 or $16 \mathrm{~d}$.

Adapted from Wiltbank et al. (1971).....

2.2 Estrus response and calving rate following 7-, 14-, or 21-d duration of progestin treatment (CIDR). Adapted from

Macmillan and Peterson (1993)

2.3 Characteristics of follicular waves during the bovine estrous cycle.

Taken from Ginther (1998).

2.4 Ovulation rate following GnRH injection on $\mathrm{d} 2,5,10,15$, or 18 of the estrous cycle. Adapted from Moreira et al. (2000)

4.1 Diagram of experimental treatments with 7 or $9 \mathrm{~d}$ CIDR, GnRH or estradiol-17 beta and progesterone, and PG or saline as main effects...23

5.1 Mean diameter of regressing, dominant, and first subordinate follicles of cows treated with estradiol-17 beta and progesterone or GnRH .29

5.2 Mean diameter of the dominant and first subordinate follicle, time of follicular wave emergence, and time of dominant follicle deviation for cows treated with estradiol-17 beta and progesterone or $\mathrm{GnRH}$

5.3 The interval from CIDR removal to estrus for cows treated with estradiol-17 beta and progesterone or GnRH, CIDR treatment for 7 or $9 \mathrm{~d}$, and PG or saline at CIDR insertion.

5.4 The regression of diameter of the dominant follicle at CIDR removal on the interval from CIDR removal to the onset of estrus

5.5 The variation in the interval from CIDR removal to estrus (synchrony of estrus) with the mean interval from CIDR removal to estrus normalized to $0 \mathrm{~h}$.

5.6 Number of standing events during estrus for cows treated with estradiol-17 beta and progesterone or GnRH, 7 or $9 \mathrm{~d}$ duration of CIDR treatment, or PG or saline administration at CIDR insertion. 


\section{List of Figures}

$\underline{\text { Figure }}$

$\underline{\text { Page }}$

5.7 Serum progesterone concentrations of cows treated with estradiol-17 beta and progesterone or $\mathrm{GnRH}$ during the first $6 \mathrm{~d}$ of experimental treatment grouped by those animals which received saline or PG at CIDR insertion................................................35

5.8 Mean serum progesterone concentrations at 0,1 , and $5 \mathrm{~d}$ following CIDR insertion, and at estrus of cows treated with either PG or saline at CIDR insertion.

6.1 A theoretical representation of the growth curve of the DF during the interval from follicular wave emergence to CIDR removal for cows treated with a CIDR for 7 or $9 \mathrm{~d}$ 


\section{Chapter 1. Introduction}

The use of artificial insemination (AI) has improved the rate of genetic change of both the beef and dairy industry. In order to promote the use of AI, estrus must be controlled in order that labor needed to breed animals can be utilized more efficiently. Synchronizing estrus can decrease the length of the breeding season, hence leading to more uniform calves at weaning.

Estrus synchronization can reduce labor during the breeding season only if animals are closely synchronized and breeding occurs within a short time following estrus synchronization treatment. If estrus and ovulation are closely synchronized, the mass mating of animals at a fixed time is feasible. Timed AI reduces the dependency on efficiency of estrus detection. An efficient estrus synchronization protocol must yield a close synchrony of estrus and ovulation and result in acceptable pregnancy rates following a single artificial insemination.

Progestins are utilized in an estrus synchronization system to inhibit estrus and ovulation. A progestin is any compound that acts in a similar fashion to progesterone. By inhibiting estrus and ovulation, progestins "hold" estrus and ovulation in animals until progestin removal at which time estrus is expressed and ovulation subsequently occurs. The mechanism of progestin induced suppression of estrus and ovulation is primarily caused by a negative feedback of the progestin on the hypothalamic-pituitary axis. This negative feedback results in depression of frequency of pulsatile GnRH secretion which precludes maturation of an ovulatory follicle which in turn inhibits the pre-ovulatory LH surge. Administering exogenous progestins, especially for long durations, has yielded a close synchrony of estrus following progestin withdrawal when luteolysis occurred during treatment; however, resulting fertility following insemination has been low.

Controlling the life-span of the corpus luteum (CL) has been the basis of estrus synchronization protocols for many years. Inducing luteolysis by administering PG synchronizes estrus in cycling cattle, but it has produced considerable variability in the timing of estrus following PG. Most animals exhibit behavioral estrus within a 5-d period following PG and fertility following PG-induced estrus has been high; however, the stage of the estrous cycle when PG is administered has influenced synchrony of estrus. Heifers treated with PG in the early stage of the cycle (d 5 to 8 ) have shown less 
variation in estrus response than those treated late in the cycle (d 14 to 16) (Stevenson et al., 1984). Consequently, manipulation of the CL alone for estrous cycle control led to considerable variability in the synchrony of estrus. It will become evident from the review of literature that controlling follicular development as well as controlling the lifespan of the CL is necessary for a close synchrony of estrus. Controlling the development of follicles prior to $\mathrm{PG}$ administration and progestin removal is the primary focus of research described in this thesis. This is currently a popular research objective among scientists investigating methods of improving reproductive efficiency in cattle by reducing the window of time in which animals initiate estrus and ovulate.

\section{Chapter 2. Review of Literature}

\section{Progestins}

Types of Progestins. Since the time estrogen (Allen and Doisy, 1923) and progesterone (Corner and Allen, 1929) were isolated and synthesized, research interests have focused on the effects of these steroids on reproduction across species of mammals. Makepeace et al. (1937) discovered exogenous progesterone would inhibit ovulation in rabbits. Eleven years later, researchers determined that exogenous progesterone would inhibit estrus in cattle (Christian and Casida, 1948). Progestational compounds, often referred to as progestins, have been used for years to synchronize estrus and ovulation in cattle (Odde, 1990; Patterson et al., 1989). Some progestational compounds include: 6chloro-6-dehydro-17-acetoxyprogesterone (CAP), dihydroxyprogesterone acetophenide (DHPA), 6-methyl-17 acetoxy-progesterone (MAP), melengestrol acetate (MGA), norethandrolone, and progesterone. Progestins have been administered orally, as injectables, via implants, and from intravaginal devices. Described below are some popular methods of progestin administration.

Early investigation of oral progestins primarily focused on inhibiting ovulation in women. In the 1960's, animal scientists began to explore the use of oral progestins to control estrus and ovulation in cattle. The only oral progestin currently approved for use in the United States by the Food and Drug Administration (FDA) is melengestrol acetate (MGA). Melengestrol acetate is a potent analog of the progestin MAP. The progestational properties of MGA were demonstrated by Zimbleman and Smith (1963) 
who maintained pregnancy in ovariectomized dairy heifers by feeding MGA. Three years later, their laboratory reported $100 \%$ suppression of estrus and ovulation in heifers fed MGA for a $16 \mathrm{~d}$ duration at a rate of $0.5 \mathrm{mg}^{*}$ head $^{-1} *$ day $^{-1}$ (Zimbleman and Smith, 1966). Feeding a progestin can be difficult, especially controlling the amount of feed intake if animal are not used to being fed from a feed bunk. Therefore, alternative ways of administering progestins have been investigated.

Devices that release progestins internally over time may be easier to utilize than attempting to regulate progestin intake through feed. One of the earliest progestinreleasing devices was a subcutaneous implant. The progestin, norgestomet, was incorporated into implants that were placed subcutaneously in the back of the ear. The implant was part of a commercially-available estrus synchronization system referred to as Syncro-Mate B (SMB; Rhone Merieux Inc., Athens, GA). The biological action of norgestomet at the cellular level was mediated via binding to progesterone receptors (Moffatt et al., 1993). The SMB treatment consisted of a norgestomet (6mg) implant, placed in the ear for a duration of $9 \mathrm{~d}$, with an injection of norgestomet $(3 \mathrm{mg})$ and estradiol valerate $(5 \mathrm{mg})$ administered at the time of implant insertion. Syncro-Mate B is no longer available; however, intravaginal progesterone-releasing devices will most likely replace the norgestomet ear implant.

One of the earliest intravaginal devices was referred to as the progesteronereleasing intravaginal device (PRID). The PRID is a silastic coil, which is impregnated with progesterone $(6.75 \%)$. Progesterone is diffused from the device into vaginal fluid and absorbed through the vaginal mucosa. The PRID was never approved for use in the United States by the FDA. The alternative to the PRID, which was recently approved for use as an estrus synchronization tool, is a new controlled internal drug-releasing device (EAZI-BREED CIDR; Pharmacia-Upjohn, Kalamazoo, MI). The CIDR, similar to the PRID, is impregnated with progesterone $(1.38 \mathrm{~g})$. In addition to the intravaginal device, the CIDR is marketed in New Zealand fitted with a gelatin capsule containing $10 \mathrm{mg}$ of estradiol benzoate.

Length of Progestin Treatment and Resulting Fertility. Early research of progestins focused on their ability to suppress and synchronize estrus. Ulberg and Lindley (1960) investigated the effect of injecting progesterone for $14 \mathrm{~d}$ on estrus 
synchrony and fertility in beef heifers. Of the heifers treated with 25 or $50 \mathrm{mg}$ of progesterone daily for a duration of $14 \mathrm{~d}, 82$ and $80 \%$ displayed estrus behavior within 10 $\mathrm{d}$ following termination of progesterone treatment, respectively. First service pregnancy rates were lower in heifers treated with higher doses $(50 \mathrm{mg})$ of progesterone than those treated with $25 \mathrm{mg}, 17.2$ and $31.2 \%$ respectively. Both treatments, however, resulted in lower conception rates than those recorded for untreated controls (50.9\%). In a similar experiment, Wiltbank et al. (1965) treated heifers with varying dosages of estrogen and progesterone for a duration of 24 days. Of the heifers treated with 20 or $40 \mathrm{mg}$ of progesterone alone, 85 and $75 \%$ displayed estrus behavior within a 4-d period following termination of injections. However, conception rates of heifers treated with either 20 or $40 \mathrm{mg}$ of progesterone (35 and 15\%, respectively), were lower than those of untreated controls $(60 \%)$.

Despite a successful synchrony of estrus, long-term progestin exposure had been linked to reduced fertility (Hansel et al., 1961; Roche, 1974). Therefore, researchers investigated the effect of decreasing the duration of progestin treatment in an effort to improve fertility. Wiltbank et al. (1971) fitted cycling beef heifers with two subcutaneous implants containing norethandrolone. Implants remained in place for a duration of either 9 or $16 \mathrm{~d}$. Heifers treated with implants for $9 \mathrm{~d}$ received an injection of estradiol valerate at implant insertion. Synchrony of estrus was similar between heifers treated with implants for a duration of 9 or $16 \mathrm{~d}$. Ninety-six hours following implant removal, 93 and $87 \%$ of heifers treated with implants for 9 or $16 \mathrm{~d}$ had exhibited estrus behavior, respectively (Figure 2.1). Pregnancy rate was greater for heifers treated for $9 \mathrm{~d}$ (61\%) than those treated for $16 \mathrm{~d}(38 \%)$. Similarly, Spitzer et al. (1978) investigated the effects of treating heifers with norgestomet implants for a duration of 9 or $16 \mathrm{~d}$ on synchrony of estrus and subsequent fertility in a series of four trials. Heifers received an implant for $9 \mathrm{~d}$ and an injection of estradiol valerate $(5 \mathrm{mg})$ at implant insertion or an implant alone for $16 \mathrm{~d}$. In two of the trials, 98 and $92 \%$ of heifers that received a implant for $9 \mathrm{~d}$ and 92 and $86 \%$ of heifers that received an implant for $16 \mathrm{~d}$ exhibited estrus behavior by $120 \mathrm{~h}$ following implant removal. Even though estrus response was similar among heifers treated with an implant for 9 or $16 \mathrm{~d}$, length of treatment significantly 
affected resulting pregnancy rates. First service conception rate was significantly higher in heifers treated with an implant for a duration of $9 \mathrm{~d}$ compared to $16 \mathrm{~d}$.

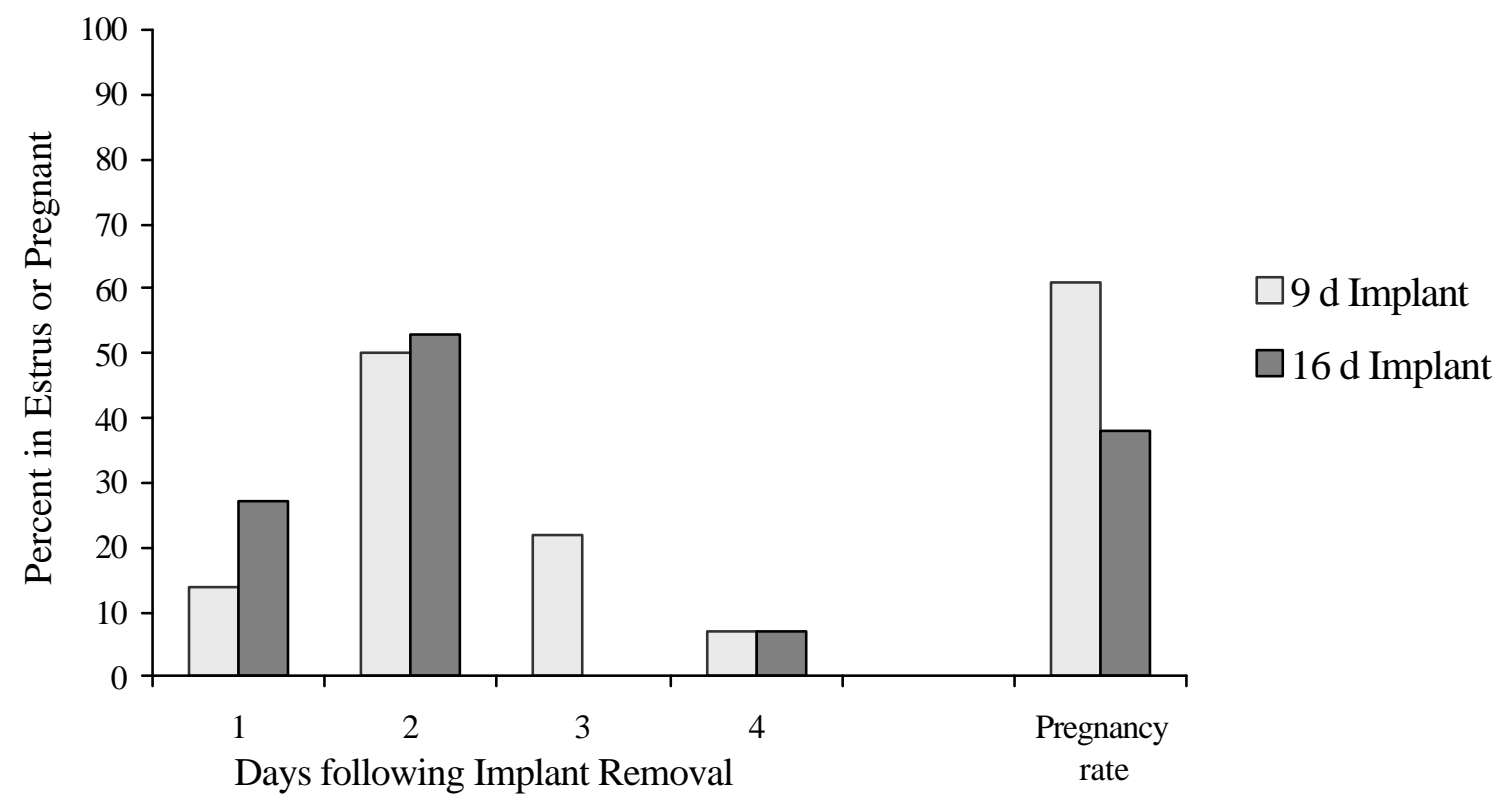

Figure 2.1. Synchrony of estrus and pregnancy rate following treatment of heifers with a norethandrolone implant for a duration of $9 \mathrm{~d}$ in conjunction with an injection of estradiol valerate at implant insertion or an implant treatment of $16 \mathrm{~d}$ alone. Adapted from Wiltbank et al. (1971).

Conception rates for heifers treated with a norgestomet implant for $9 \mathrm{~d}$ were 71 and $61 \%$ verses 30 and $35 \%$ for heifers treated for $16 \mathrm{~d}$, respectively.

The synchrony of estrus resulting from a progestin treatment duration of $9 \mathrm{~d}$, in conjunction with the administration of estradiol valerate at implant insertion, was similar to the synchrony of estrus resulting from longer treatment durations. However, resulting conception rates have been higher in heifers treated with a progestin for $9 \mathrm{~d}$. From these findings, the SMB estrus synchronization system became an acceptable and commercially-available method to synchronize estrus. Odde (1990) reviewed numerous trials using SMB to synchronize estrus in cattle and reported a range in estrus response from 77 to $100 \%$ with a range in pregnancy rates from 30 to $63 \%$.

All short-term ( $9 \mathrm{~d}$ treatment duration) progestin treatments described thus far have included an injection of estradiol valerate at implant insertion. Humphrey et al. 
(1977) investigated the effects of inclusion of estradiol valerate at the start of the SMB treatment. Puberal, crossbred beef heifers were fitted with a subcutaneous, norgestomet (6 mg) implant for a duration of $9 \mathrm{~d}$. One half of the animals received an injection of estradiol valerate $(5 \mathrm{mg})$ and norgestomet $(3 \mathrm{mg})$ at implant insertion and the other half received only an injection of norgestomet $(3 \mathrm{mg})$. Heifers treated with estradiol valerate at implant insertion tended to have a greater estrus response and conception rate $(82 \%$ and $45 \%$, respectively) than heifers that received no estradiol valerate $(69 \%$ and $26 \%$, respectively).

Part of the range in estrus response and conception rates following SMB treatment was explained by the stage of the estrous cycle at which SMB treatment was initiated. Pratt et al. (1991) investigated the effects of injecting 5 or $6 \mathrm{mg}$ of estradiol valerate at the beginning of a norgestomet implant treatment ( 9 d duration) on $d 1,3$, or 5 of the estrous cycle on synchrony of estrus and pregnancy rate. Cows treated on $\mathrm{d} 1 \mathrm{had}$ a higher estrus response (58\%) and first-service pregnancy rate $(63 \%)$ than those treated on d 5 (31 and 33\%, respectively). In a separate experiment (Pratt et al., 1991), cows were treated on $\mathrm{d} 3$ or 9 of the estrous cycle with varying dosages of estradiol valerate $(5,7$, or $9 \mathrm{mg}$ ) at implant insertion. There was no effect of estradiol valerate dosage on synchrony of estrus; however, significantly more cows treated on d 9 of the estrous cycle exhibited estrus behavior by $96 \mathrm{~h}$ following implant removal than those treated on $\mathrm{d} 3$ (91 vs. 62\%). Despite differences in estrus response, day of the estrous cycle when treatment was initiated had no effect on pregnancy rate across all doses of estradiol valerate treatment. In a similar experiment utilizing the standard SMB protocol, Brink and Kiracofe (1987) reported no differences in the interval from implant removal to estrus or the synchrony of estrus between cows treated early $(\leq \mathrm{d} 11)$ or late $(>\mathrm{d} 11)$ in the estrous cycle. First service conception rate, however, tended to be higher in cows treated early in the cycle (47\%) when compared to those treated late in the cycle $(37 \%)$. Due to the number of animals $(n=38, n=47)$ grouped per stage of the estrous cycle, conclusive inferences on the effect of stage of the estrous cycle were difficult to ascertain.

The optimal duration of progestin treatment has been difficult to determine. Treating cattle with progestins for durations of 16 to $24 \mathrm{~d}$ has produced a high estrus response, but resulted in a detrimental effect on fertility compared to a 9-d treatment. 
Researchers began to investigate the effects of length of progestin exposure to increase fertility. Macmillan and Peterson (1993) treated 748 heifers, across nine herds, with CIDRs inserted for a duration 7, 14, or $21 \mathrm{~d}$. Heifers that received a CIDR for a duration of $7 \mathrm{~d}$ were administered PG at CIDR removal. Prostaglandin was administered to heifers receiving the 7-d treatment to regress any corpora lutea present at CIDR removal. The corpora lutea of heifers treated for 14 or $21 \mathrm{~d}$ were assumed to have regressed or were regressing at the time of CIDR removal. Macmillan and Peterson (1993) reported synchrony of estrus increased and calving rate decreased as the duration of CIDR treatment increased (Figure 2.2).

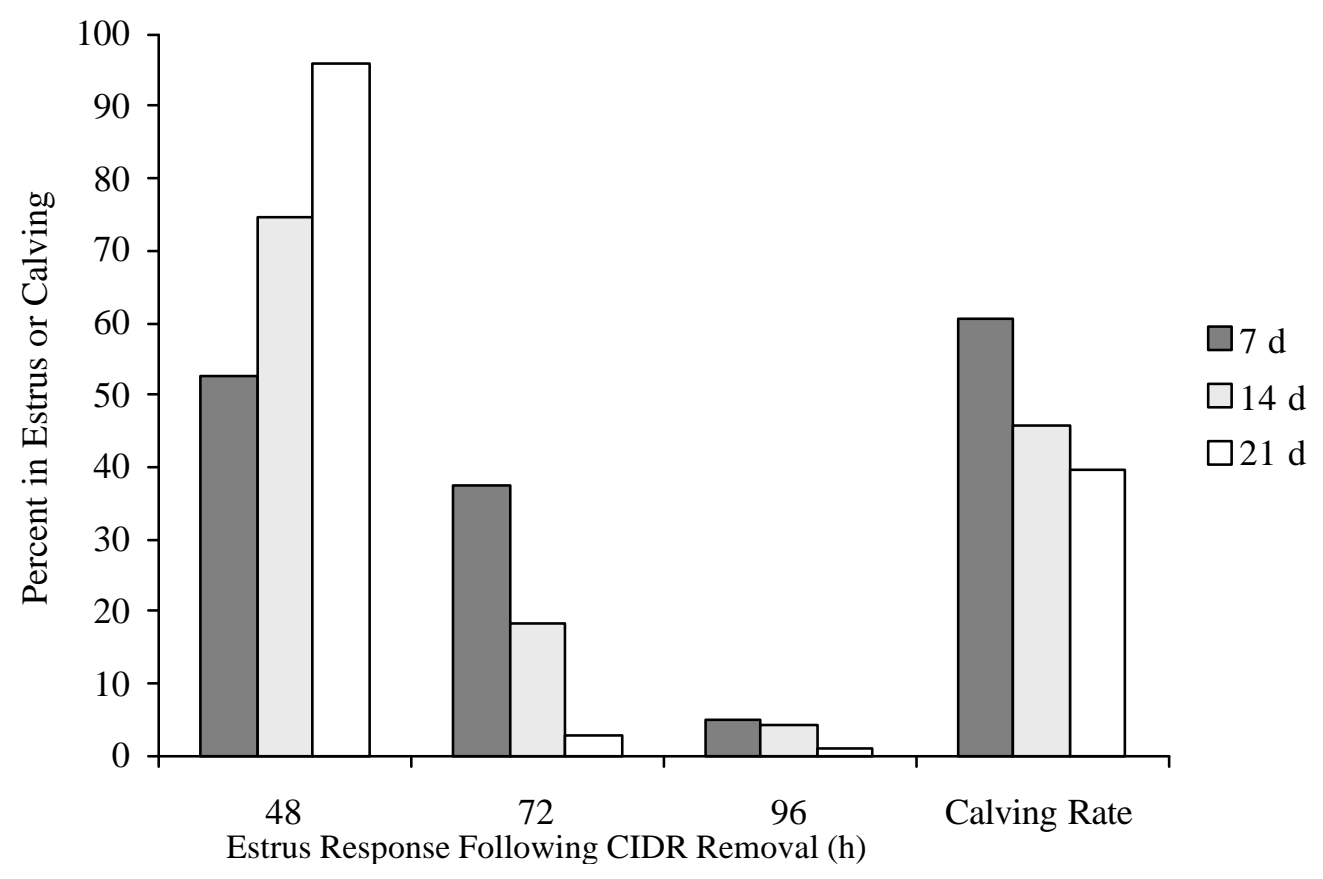

Figure 2.2. Estrus response and calving rate following 7-, 14- or 21-d duration of progestin(CIDR)treatment. Cows treated with a CIDR for $7 \mathrm{~d}$ received an injection of PG at CIDR removal. Adapted from Macmillan and Peterson (1993).

Based on the results of Macmillan and Peterson (1993), shortening the duration of CIDR treatment to $7 \mathrm{~d}$ resulted in higher fertility for the estrus period following CIDR removal compared to treatments with longer durations. Smith et al. (1984) decreased the duration of progestin treatment to $6 \mathrm{~d}$ and compared the resulting estrus response and pregnancy rates to that of animals receiving a $7 \mathrm{~d}$ treatment duration. Holstein heifers were fitted with a PRID for a duration of either 6 or $7 \mathrm{~d}$. Heifers that received the 6-d 
treatment duration were administered a single injection of PG at PRID removal (PRID6+PG-6) whereas heifers that received the $7 \mathrm{~d}$ treatment duration received PG $1 \mathrm{~d}$ prior to PRID removal (PRID-7+PG-6). No differences in the estrus response existed between treatments. Heifers treated with the PRID-7+PG-6 yielded a tighter synchrony of estrus than those that received the PRID-6+PG-6. However, pregnancy rate did not differ between PRID-7+PG-6 (73\%) and PRID-6+PG-6 (82\%) treatments, and pregnancy rates of heifers in both PRID treatments did not differ from those of untreated controls (72\%).

Long-term progestin treatment has consistently yielded a tight synchrony of estrus but has been detrimental to fertility. Some estrus synchronization systems, utilizing MGA treatment, have exposed heifers or cows to long-term progestin treatment and resulted in a high estrus response, tight synchrony of estrus, and normal fertility. The key to these systems has been to forgo breeding of animals at the estrus immediately following progestin treatment, and to re-synchronize animals with a single injection of PG at a later time. Patterson et al. (1995) investigated the effects of treating postpartum, suckled beef cows with MGA and PG verses PG on synchrony of estrus and conception rate. Cows were fed MGA at a rate of $0.5 \mathrm{mg}^{*} \mathrm{head}^{-1} * \mathrm{day}^{-1}$ or a carrier feed for a duration of $14 \mathrm{~d}$. All cows received a single injection of PG $17 \mathrm{~d}$ after the termination of MGA or carrier feeding. Feeding cows MGA prior to PG resulted in a greater estrus response compared to those that did not receive MGA. In addition, cows treated with MGA had a higher conception rate than those that received PG alone. Increasing the interval from the termination of MGA feeding to PG has increased the synchrony of estrus following PG. Kelser et al. (1996) reported that heifers administered PG $17 \mathrm{~d}$ following MGA treatment termination had a higher percentage of corpora lutea that had regressed following PG than those that received PG $13 \mathrm{~d}$ following MGA. Therefore, increasing the interval between MGA and PG increased the responsiveness of corpora lutea to PG. Lamb et al. (2000) also investigated the effect of increasing the interval from MGA treatment termination to PG from 17 to $19 \mathrm{~d}$. Heifers were fed MGA for $14 \mathrm{~d}$ followed 17 or $19 \mathrm{~d}$ later by PG and each heifer was artificially inseminated 12 to $16 \mathrm{~h}$ following the onset of behavioral estrus. More heifers were inseminated $72 \mathrm{~h}$ following PG in the group that received PG $19 \mathrm{~d}$ following MGA termination than those that received $\mathrm{PG}$ at $17 \mathrm{~d}$. By increasing the interval from MGA termination to PG thus 
increasing the potential of the CL to respond to PG, Lamb et al. (2000) increased the synchrony of estrus.

Improving the synchrony of estrus following progestin treatments has led to the possibility of mass mating animals at a single time (timed AI) resulting in acceptable fertility. Roche (1976) treated suckled beef cows with two injections of PG, $12 \mathrm{~d}$ apart or a PRID for a duration of $12 \mathrm{~d}$ in conjunction with an injection of estradiol benzoate ( 5 $\mathrm{mg}$ ) and progesterone (200 $\mathrm{mg}$ ) at PRID insertion. Cows that received two injections of PG were inseminated at 72 and $96 \mathrm{~h}$ following the second PG injection. Cows that received a PRID were inseminated at 56 and $74 \mathrm{~h}$ following PRID removal. Cows treated with a PRID and estradiol benzoate and progesterone at PRID insertion had a higher pregnancy rate $(56 \%)$ than those that received two injections of PG $(32 \%)$. Smith et al. (1984) compared pregnancy rates resulting from timed AI of heifers treated with a PRID or PG verses those bred 8 to $20 \mathrm{~h}$ following spontaneous estrus. Heifers were assigned to the following treatments: 1) no treatment (control), 2) PRID for $7 \mathrm{~d}$ duration with PG $1 \mathrm{~d}$ prior to PRID removal (timed AI $84 \mathrm{~h}$ after PG), or 3) two injections of PG $11 \mathrm{~d}$ apart (time AI $80 \mathrm{~h}$ after PG). Pregnancy rate of heifers treated with a PRID (66\%) was not different from untreated controls $(73 \%)$, but was higher than that of those that received two injections of PG (52\%).

The SMB protocol was one of the first successful timed AI systems. Odde (1990) reviewed numerous trials of the efficacy of timed AI following SMB. Five-day pregnancy rate was similar between groups of animals bred relative to estrus and those that were inseminated at a single, pre-set time (timed AI). Five-day pregnancy rate from timed AI following SMB treatment ranged from 39 to 62\%. Data from Smith et al. (1984) and data reviewed from Odde (1990) indicated that pregnancy rate following a progestin treatment and timed AI yielded similar results to animals bred relative to estrus.

Lowered Fertility Associated with Progestin Treatment. Incorporating progestins into an estrus synchronization treatment has been shown to produce high estrus responses and a close synchrony of estrus. Shortening the duration of progestin exposure $(<9 d)$ resulted in pregnancy rates that were similar to estrus synchronization systems utilizing PG alone. Despite the close synchrony of estrus yielded by long term ( $>9 \mathrm{~d}$ ) progestin treatments, fertility was clearly reduced. Reduced fertility from long term progestin 
exposure has been shown to be due to development of a persistent dominant follicle. Before describing the persistent dominant follicle in more depth, it is imperative to have an understanding of follicular events occurring during the bovine estrous cycle.

\section{Follicular Events During the Bovine Estrous Cycle}

The bovine estrous cycle typically ranges in duration from 17 to $24 \mathrm{~d}$ (Senger, 1997). The estrous cycle can be divided into two stages, the follicular and luteal phase. The lifespan of the CL defines the length of the diestrus or luteal phase. The end of luteal phase and regression of the CL leads to initiation of the follicular phase during which behavioral estrus occurs. Although the CL is the dominant structure on the ovary during the majority of the estrous cycle, follicles grow and regress throughout the cycle. The pattern of follicular development and regression has been termed a follicular wave.

In 1960, Rajakoski hypothesized that follicles grew on the ovary in a wave like manner with the most likely pattern being two waves during the estrous cycle. Early research of ovarian events was somewhat limited because ovaries could only be examined postmortem or via surgery. With the use of transrectal ultrasonography, ovarian events could be monitored more precisely in vivo. Pierson and Ginther (1984) were among the first to classify and document events on the bovine ovary using transrectal ultrasonography. Rajakoski's two-wave hypothesis was supported by Pierson and Ginther (1987) when they categorized follicles by diameter for each day of the estrous cycle. They noted the evolution of two large follicles (one for each follicular wave), a anovulatory follicle for the first wave and an ovulatory follicle for the second wave, during the course of the estrous cycle. Prior to the appearance of the large follicles, they reported the appearance of a pool or cohort of small follicles $(>4 \mathrm{~mm}$ in diameter). Furthermore, there was an inverse relationship between diameter of the largest follicle and the second largest follicle from $\mathrm{d} 4$ to $\mathrm{d} 8$ following ovulation indicating the future large, anovulatory or ovulatory follicle differentiated in size from other follicles of the pool. All of these characteristics were indicative of a two-follicular wave estrous cycle. Other researchers have shown the presence of three follicular waves during the bovine estrous cycle (Fortune et al., 1988; Knopf et al., 1989).

The characteristics of a two-follicular wave estrous cycle are depicted in Figure 2.3. In a two-wave estrous cycle, the anovulatory follicle, of the first wave, undergoes 


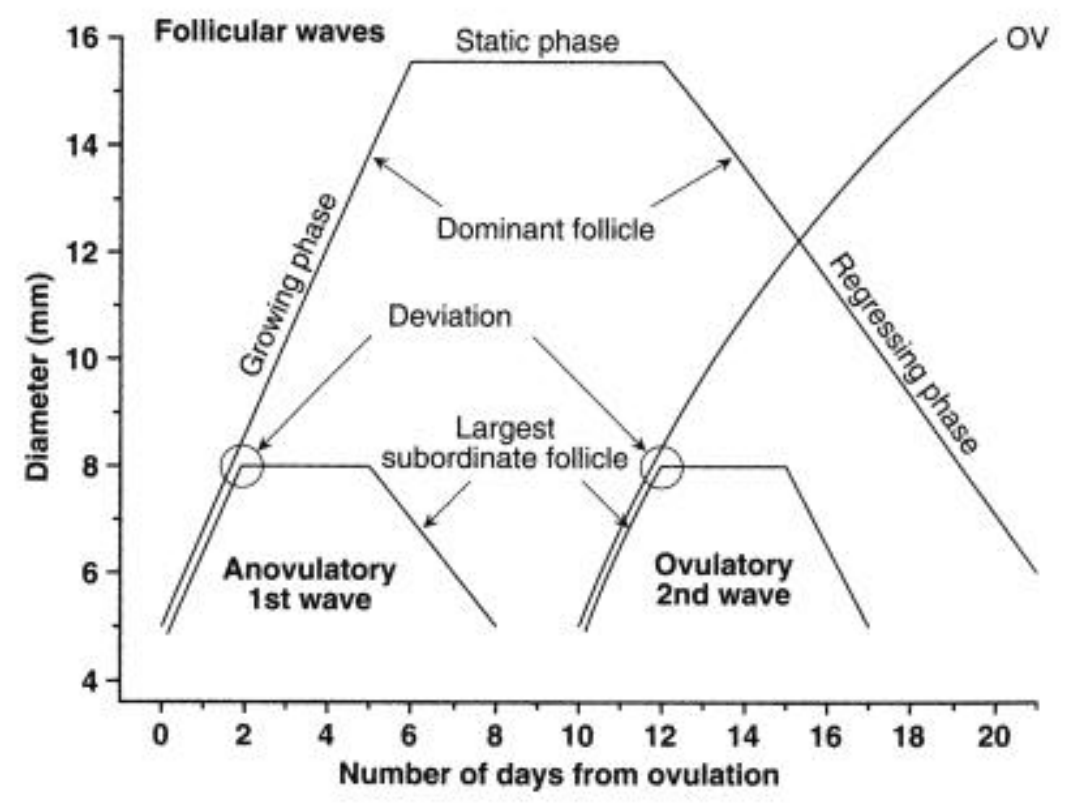

Figure 2.3. Characteristics of follicular waves during the bovine estrous cycle. Taken from Ginther (1998; with permission).

three stages of development: the growing, static, and regressing phases (Ginther et al., 1989). In contrast, the ovulatory follicle undergoes the growing phase and proceeds to ovulation. The beginning of the growth phase is characterized by the appearance of a pool of small follicles. The appearance of a pool of follicles ( $4 \mathrm{~mm}$ in diameter) is termed emergence (Ginther et al., 1996). During a two-wave cycle, emergence of follicles in the anovulatory and ovulatory waves occurs at 0.1 and $9.8 \mathrm{~d}$ following ovulation, respectively. During a three-wave cycle, emergence of the first, second, and third wave occur on $\mathrm{d}$ 1.9, 9.4, and 16.1 of the cycle, respectively (Fortune et al., 1988).

Growth of the newly emerged cohort of follicles continues until $2.8 \mathrm{~d}$ following ovulation, at which time deviation of the dominant follicle (DF) occurs. Deviation is defined as the time the largest follicle and second largest follicle exhibit their greatest difference in growth rate or when the second largest follicle reaches its maximum diameter (Ginther et al., 1996). Following deviation, subordinate follicles begin to regress or decrease in diameter.

From an endocrine standpoint, two major events occur up to and at the time of deviation. One to two days prior to wave emergence, a surge in FSH occurs. It is during the decline in circulating FSH, following the FSH surge, that emergence occurs 
(Ginther et al., 1996). The FSH surge, which occurs prior to follicular wave emergence, sustains the cohort of follicles until around the time of deviation.

The mechanism of deviation has been heavily investigated from a morphological and molecular standpoint. Ginther et al. (1996) postulated two possible mechanisms controlling deviation. The first theory hypothesized that the DF actively suppressed subordinate follicles through suppression of FSH. The second theory postulated that the DF changed from FSH to LH dependency. Theoretically, the switch in dependency from FSH to LH by the DF has been supported by comparatively examining follicle growth rate, mRNA expression, and IGF-1 and IGF binding proteins (IGFBP) in follicular fluid at the time of deviation.

Deviation of the DF is characterized by an increased difference of growth rate and diameter between the dominant and subordinate follicles. During the $16 \mathrm{~h}$ interval prior to deviation, the growth rate of the DF and second largest or first subordinate follicle has been reported to increase above that of remaining subordinate follicles (Ginther et al., 2001). Following deviation, the DF continued to grow and all subordinate follicles began a reduction in size. In a review of follicle selection in monovular species, Ginther et al. (2001b) reported, in a number of experiments, the average size of the DF at deviation in cattle was $8.5 \mathrm{~mm}$.

The gonadotropins, LH and FSH are an intricate part of the mechanism of deviation. Ginther et al. (1996) suggested that deviation was caused by a decline in FSH and a switch by the DF in dependency from FSH to LH. However, because subordinate follicles are FSH dependent, they regress following deviation because FSH has reached basal levels by that time. Adams et al. (1993) demonstrated the dependency of subordinate follicles on FSH for survival. Administering FSH for $2 \mathrm{~d}$ when the largest follicle was $6 \mathrm{~mm}$, caused a delay in the time of deviation by $2 \mathrm{~d}$. At the time of deviation while subordinate follicles begin to regress from lack of FSH, the future DF acquires $\mathrm{LH}$ receptors (LHr) that allow it to continue its increase in growth and estrogen production. Beg et al. (2001) reported that at around $8.5 \mathrm{~mm}$, the granulosa cells of the future DF expressed a greater level of LHr mRNA than subordinate follicles. In addition, they reported a decrease in IGF-1 and a progressive increase in IGFBP-2 when subordinate follicles were 7.5 to $11.2 \mathrm{~mm}$ in diameter. Increased expression of $\mathrm{LHr}$ 
mRNA indicated the acquisition of $\mathrm{LH}$ receptors on the DF. At the time of deviation, decreasing IGF-1 and decreasing IGFBP-2 in subordinate follicles provided supporting evidence that these follicles were "shutting down" and regression was beginning. In a review of folliculogenesis, Roche et al. (1996) noted that IGF-1 may play an important role in steroidogenesis, selection, and dominance of follicles.

Following deviation, the DF of the anovulatory wave continues to grow until d 6 , at which time it enters the static phase and the linear increase in growth ceases (Ginther et al., 1989). It is during the static phase that the DF loses functional dominance and the next follicular wave emerges (d 9.8). At approximately d 12, the DF of the anovulatory wave begins the regression phase. The ovulatory DF continues to grow until removal of the progesterone negative feedback (CL regression) on the hypothalamic-pituitary axis and occurrence of the pre-ovulatory LH surge and ovulation (Senger, 1997).

The phenomenon of follicular waves during the bovine estrous cycle is clearly a complex and intricate series of events. Understanding the basic events provides a better foundation for controlling estrus and ovulation. These events will be subject to investigation for years to come.

The Persistent Follicle Revisited

A persistent follicle is a DF that remains in the static phase, exhibits prolonged functional dominance, and fails to regress. The follicle remains estrogen-active, meaning it continues to synthesize aromatase in the granulosa cells of the follicle and secrete estrogen. The aromatase enzyme is responsible for converting androgens, produced in the thecal cells of the follicle, to estrogen. Follicle stimulating hormone stimulates cAMP to transcribe aromatase mRNA in follicles prior to deviation. At deviation, the DF acquires LH receptors, and LH stimulates increased aromatase mRNA transcription and consequent estrogen production. In fact, some researchers reported that persistent follicles secreted more estradiol than dominant follicles that were not persistent (Savio et al., 1993). The cause of increased estrogen production was most likely due to increased number and mass of granulosa and thecal cells adverse to increased steroidogenic activity (Bigelow and Fortune, 1998). Meaning, larger amounts of estrogen were due to a greater number of cells that are producing it; however, the steroidogenic activity of individual cells was not increased. 
Persistence of a follicle has been demonstrated to be caused by increased pulsatile LH secretion. Frequency of pulsatile release of LH has been reported to be affected by levels of circulating progesterone (Rahe et al., 1980). In the absence of a CL, most commonly-used progestin sources have delivered an amount of progestin that was lower than the amount produced by the CL during the natural estrous cycle. Subluteal levels of progesterone have inhibited the pre-ovulatory LH surge but failed to suppress the enhanced pulsatile secretion of LH (Roberson et al., 1989). Cattle administered one CIDR exhibited increased LH pulse frequency compared to those administered two CIDRs (Stock and Fortune, 1993). The increased pulse frequency of LH is responsible for prolonged maintenance of a DF. Taft et al. (1996) reported the incidence of prolonged follicle growth was due to increased LH pulse frequency independent of circulating progesterone concentrations. Beef cows were administered bovine LH (50 mcg) every $2 \mathrm{~h}$ from $\mathrm{d} 7$ to $\mathrm{d} 13$ of the estrous cycle. Treating cows with LH during the normal luteal phase increased the length of dominance and diameter of the follicle present at treatment initiation.

Luteinizing hormone is a key factor in growth and estrogen production of the DF after deviation, and endogenous or exogenous progestin levels regulate its pattern of release. Sirois and Fortune (1990) prolonged growth of a DF by administering low levels ( 1 to $2 \mathrm{ng} / \mathrm{ml}$ ) of exogenous progesterone. Heifers were treated with a blank CIDR, one CIDR, or two CIDRs for a duration of $14 \mathrm{~d}$ starting on $\mathrm{d} 14$ of the estrous cycle. Dominant follicles of heifers treated with one CIDR were present longer and attained a larger diameter than those treated with 2 CIDRs or controls (Table 2.1). Similarly, Noble et al. (2000) created estrogen-active follicles that persisted under the treatment of low levels of exogenous progesterone. Low levels of exogenous progesterone were administered by a PRID that contained $0.78 \mathrm{~g}$ progesterone or approximately half the amount of progesterone as a normal PRID (0.5 PRID). Heifers were treated with 0.5 PRID, starting on d 15 of the estrous cycle, for a duration of $25 \mathrm{~d}$. In one half of the animals, the 0.5 PRID was removed and replaced with a new 0.5 PRID on $\mathrm{d} 13$ of the experimental treatment. The DF that emerged within the first $5 \mathrm{~d}$ following 0.5 PRID insertion remained $>10 \mathrm{~mm}$ in diameter for a duration of $15.3 \pm 1.7 \mathrm{~d}$ in heifers treated 
with a single 0.5 PRID for $25 \mathrm{~d}$ compared to $11.6 \pm 0.4 \mathrm{~d}$ in heifers where the $0.5 \mathrm{CIDR}$ was replaced.

Table 2.1. The effect of treatment with varying levels of exogenous progesterone (blank, one, and two CIDR treatment) for a duration of $14 \mathrm{~d}$, started on d 14 of the estrous cycle, on the dynamics of the ovulatory follicle. Adapted from Sirois and Fortune (1990).

\begin{tabular}{cccc}
\cline { 2 - 4 } & Blank CIDR & 1 CIDR & 2 CIDRs \\
\hline Maximal size (mm) & $14.3 \pm 0.4^{\mathrm{a}}$ & $19.7 \pm 0.2^{\mathrm{b}}$ & $17.1 \pm 1.1^{\mathrm{c}}$ \\
Dominance phase (d) & $3.8 \pm 0.5^{\mathrm{a}}$ & $11.2 \pm 1.2^{\mathrm{b}}$ & $5.2 \pm 0.9^{\mathrm{a}}$ \\
Present as the largest follicle (d) & $3.0 \pm 1.0^{\mathrm{a}}$ & $9.8 \pm 0.6^{\mathrm{b}}$ & $4.5 \pm 1.6^{\mathrm{a}}$ \\
\hline
\end{tabular}

*Data within each row with different superscripts differ significantly $(\mathrm{P}<0.05)$.

The greatest problem posed by development of persistent follicles during estrus synchronization is the potential for reduced fertility. Savio et al. (1993) reported pregnancy rates following ovulation of a persistent follicle were reduced. In their experiment, Holstein heifers were pre-synchronized with two injections of PG given $11 \mathrm{~d}$ apart. On $\mathrm{d} 7$ of the subsequent estrous cycle, heifers received a single injection of PG or a previously used CIDR for duration of $9 \mathrm{~d}$. "Used" CIDRs had been used previously for a duration of $9 \mathrm{~d}$. The rationale of using a "used" CIDR was to create a low-level progesterone environment in which persistent follicles would develop during the period in which the "used" CIDR was in place. First service conception rate of heifers that received the "used" CIDR and were bred relative to estrus were $37.1 \%$ compared to those receiving a single injection of PG (64.8\%). Austin et al. (1999) confirmed the negative effect of prolonged follicle growth on pregnancy rates by varying the duration of follicle dominance. On the day the DF of the second follicular wave became dominant $(\geq 8.5$ $\mathrm{mm}$ diameter), heifers received an injection of PG and were fitted with a norgestomet (3 mg) ear implant for periods that created an expected duration of dominance of 2, 4, 6, 8, 10 , or $12 \mathrm{~d}$. Extending the duration of dominance of the ovulatory follicle to 10 and $12 \mathrm{~d}$ decreased pregnancy rates compared to 2-d duration of dominance (52 and 12\% vs. 90\%, respectively). 
The cause of reduced fertility from persistent follicles may be associated with hormonal changes, specifically LH, affecting the oocyte and surrounding oocyte complex (cumulus cells). The incidence of reduced fertility may be related to over-exposure of the oocyte to $\mathrm{LH}$ and consequent premature maturation of the oocyte relative to fertilization. Revah and Butler (1996) reported that oocytes recovered from persistent follicles had undergone premature nuclear maturation (cumulus cell expansion and condensed chromatin). Mihm et al. (1999) investigated the nuclear morphology of cattle oocytes recovered from follicles that persisted for a duration of $>9 \mathrm{~d}$. In that experiment, heifers were treated with PG and a norgestomet ( $3 \mathrm{mg}$ ) implant for a duration of 2 or $10 \mathrm{~d}$ at the time of deviation in the second follicular wave. Their results indicated that final oocyte maturation (germinal vesicle breakdown and progression to metaphase I) had occurred in most follicles in which dominance was prolonged for $>9 \mathrm{~d}$.

The initiation of final oocyte maturation in persistent follicles is due to over exposure to LH. Dominko and First (1997) reported oocytes matured in vitro in the presence of LH had an increased speed of nuclear maturation compared to those matured in the presence of FSH. Early maturation of the oocyte is caused by removal of the meiotic block which keeps the oocyte arrested at the dictyate phase of prophase. In the normal situation, meiotic inhibition is mediated by the inner most layer of cumulus cells associated with the oocyte. Following the pre-ovulatory LH surge, expansion of the cumulus cells and final oocyte maturation occurs (Szollosi, 1993). Bochert et al. (1999) reported oocytes from cows with persistent follicles, induced by a $10 \mathrm{~d}$ administration of norgestomet implants in the absence of a CL, underwent cumulus expansion sooner after ovulation than oocytes from follicles that were not persistent. Similarly, Revah and Butler (1996) reported early cumulus cell expansion associated with persistent follicles. Thus, dispersion of cumulus cells may reflect the premature removal of the meiotic block leading to continuation of oocyte maturation and reduced oocyte fertility (Szollosi, 1993). In summary, it is clear that persistence of the DF leads to reduced fertility. The cause of lowered fertility is likely due to prolonged exposure of the follicle and oocyte to higher than normal LH pulse frequency relative to the mid luteal phase. Reduced fertility due to LH exposure is likely due to premature nuclear maturation of the oocyte prior to ovulation and fertilization. The mechanism initiating premature resumption of meiosis in 
the persistent follicle is likely mediated by the same process initiated by the pre-ovulatory LH surge.

\section{Controlling Follicle Emergence}

Using progestins to synchronize estrus produces a close synchrony and high estrus response. In order to attain acceptable conception rates following progestin use to synchronize estrus though, the ovulatory follicle must be controlled to avoid formation of persistent follicles. The ability to initiate or "turnover" a follicular wave during a progestin treatment significantly decreases the possibility of developing persistent follicles. Two common methods that result in turnover of a follicular wave are administration of GnRH or the combination of estrogen and progesterone.

Gonadotropin-Releasing Hormone. Analogs of GnRH are available commercially and sold under the names Cystorellin, Fertagyl, and Factrel. The original, FDA-approved use of these products was for treatment of follicular cysts (Kittok, et al., 1973). Administration of exogenous GnRH has the same effect as the mechanism causing the endogenous pre-ovulatory LH surge. The surge in GnRH from the hypothalamus or exogenous administration of $\mathrm{GnRH}$ causes the anterior pituitary to release $\mathrm{LH}$. The LH surge is followed by the events of ovulation and luteal structure formation.

Administration of exogenous GnRH removes the DF from the ovary by causing ovulation to occur. Following the loss of dominance (after induced ovulation) of the DF, a new follicular wave emerges. Macmillan and Thatcher (1991) reported administration of the GnRH agonist Buserelin (10 mcg) was followed by a decrease in the number of large follicles, but an increase in the number of medium size follicles on the bovine ovary. Induction of ovulation following administration of Buserelin was variable though. Following administration of GnRH, emergence of a new follicular wave occurs on average 1.5 d later (Bentley et al., 1998; Martinez et al., 1997). However, when cows were treated at random stages of the estrous cycle, the interval from treatment to emergence was quite variable. Martinez et al. (1997) reported a range of -1 to $4 \mathrm{~d}$ in the interval from GnRH treatment to new wave emergence when GnRH was administered at random stages of the estrous cycle. 
By combining the use of GnRH and PG, a timed breeding synchronization program called Ovsynch was developed by Pursley et al. (1997). The Ovsynch protocol has yielded pregnancy rates of 35.1 and $37.8 \%$ in heifers and cows, respectively (Pursley et al., 1997). In the Ovsynch protocol, $\mathrm{PG}$ is administered $7 \mathrm{~d}$ following a single injection of GnRH. Forty eight hours following PG, a second injection of GnRH is administered. Animals are mass inseminated 16 to $20 \mathrm{~h}$ following the second GnRH injection. The purpose of the first GnRH injection is to induce ovulation and subsequent emergence of a new follicular wave; whereas the purpose of the second injection of $\mathrm{GnRH}$ is to induce ovulation and facilitate mass mating of the animals.

In dairy heifers, ovulation rate following the first GnRH injection has been lower than that recorded in cows (59.5 vs. 85\%) (Pursley et al., 1995). Ovulation failure following the first GnRH injection has been attributed to the stage of the estrous cycle at which GnRH was administered. Macmillan and Thatcher (1991) reported inconsistencies in ovulation rate following $\mathrm{GnRH}$ administration. Ovulation rates from heifers treated with $\mathrm{GnRH}$ on $\mathrm{d} 12$ of the cycle were 48, 0, and $76 \%$ during three different experiments. Moreira et al. (2000) reported a decrease in ovulation rate with heifers administered GnRH on d 2 or $\mathrm{d} 10$ of the estrous cycle (Figure 2.4). Therefore,

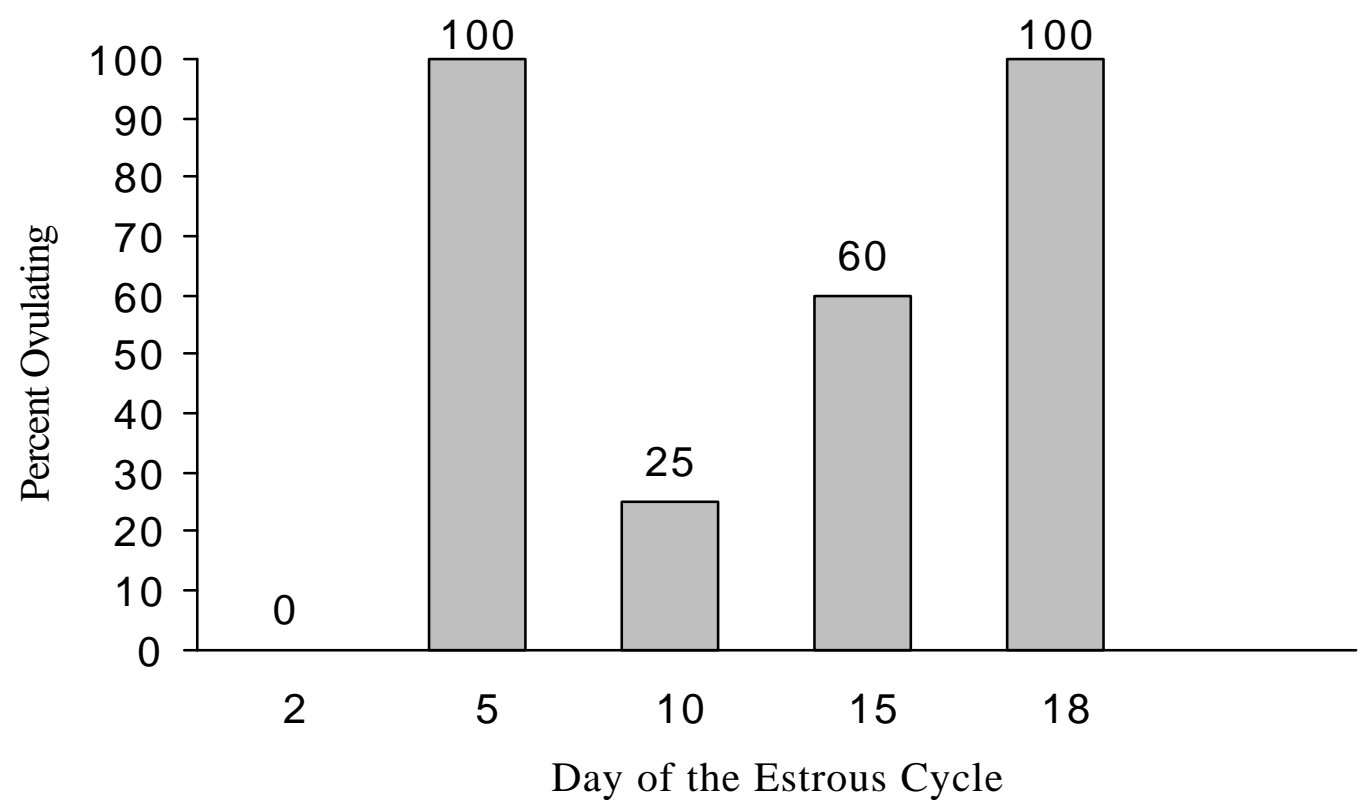

Figure 2.4. Ovulation rate following GnRH injection on d 2, 5, 10, 15, or 18 of the estrous cycle. Adapted from Moreira et al. (2000). 
GnRH was ineffective at d 2 or d 10 of the estrous cycle when deviation of the first- and second-wave DF had not yet occurred. Prior to deviation, the DF of each follicular wave had not been selected and all follicles present were still FSH-dependent. The DF follicle does not acquire LH receptors until deviation has occurred (Ginther et al., 1996). Therefore, initiating an LH surge, via exogenous $\mathrm{GnRH}$, will not cause ovulation at those stages of the estrous cycle where a follicular wave has emerged, but deviation of the DF has not occurred. The variation in responsiveness to a GnRH-induced LH surge is most likely the cause of variation in the time from $\mathrm{GnRH}$ treatment to emergence reported by Martinez et al. (1997) and Bently et al. (1998).

Estradiol. Researchers had incorporated injections of estradiol at the start of progestin-based estrus synchronization treatments. Administering estradiol valerate at the start of 9-d norgestomet implant period tended to increase conception rate compared to the use of the implant alone (Humphrey et al., 1977). Researchers originally incorporated estradiol at the start of progestin treatments to take advantage of its luteolytic action. However, estradiol was later shown to be an effective method of suppressing growth of a DF and inducing emergence of a new follicular wave.

Unlike GnRH, estradiol induces development of a new follicular wave without causing ovulation. The ability of estradiol to initiate a new follicular wave was more consistent when estrogens were administered in conjunction with a progestin. Bo et al. (1994) reported the FSH surge prior to emergence and new follicular wave emergence occurred earlier in heifers treated with a norgestomet implant and estradiol-17 beta compared to those treated with estradiol without an implant. In addition, estradiol is effective at inducing new follicular wave emergence before and after the time of deviation of a DF. Bo et al. (1993) reported estradiol valerate treatment terminated the growth phase of the DF when administered at 1 or $3 \mathrm{~d}$ following ovulation.

Emergence of a new follicular wave following estradiol treatment occurs at a later time relative to treatment compared to administration of GnRH. Bridges et al. (1999) reported emergence of a new follicular wave occurred between 3.3 and 3.9 d following injection of estradiol valerate and insertion of an intravaginal progesterone insert. Similarly, Martinez et al. (1997) reported emergence of a new follicular wave occurring $3.4 \mathrm{~d}$ following estradiol-17 beta and progesterone administration (Table 2.2). In the 
same experiment, the variation around the mean time of emergence was significantly less in heifers treated with estradiol-17 beta and progesterone compared to those treated with GnRH.

Table 2.2. Time to follicular wave emergence following treatment with estradiol-17 beta and progesterone, GnRH, or follicle ablation. Adapted from Martinez et al. (1997).

\begin{tabular}{cccc}
\cline { 2 - 4 } & $\mathrm{E}_{2}+\mathrm{P}_{4}$ & GnRH & Follicle Ablation \\
\cline { 2 - 4 } & $3.4 \pm 0.1^{\mathrm{a}}$ & $1.5 \pm 0.3^{\mathrm{b}}$ & $1.0 \pm 0.1^{\mathrm{b}}$ \\
\hline $\begin{array}{c}\text { Treatment to wave } \\
\text { emergence (d) } \\
\text { Range (d) }\end{array}$ & 3 to $4^{\mathrm{a}}$ & -1 to $4^{\mathrm{b}}$ & 0 to $2^{\mathrm{a}}$ \\
\hline
\end{tabular}

*Means and variances with uncommon superscripts within rows differ $(\mathrm{P}<0.05)$.

The mechanism of estradiol-induced regression of the DF is different from that of GnRH. Administering estradiol following luteolysis will induce estrus behavior, the preovulatory LH surge, and ovulation of the dominant follicle (Lammoglia et al., 1998). Following the administration of estradiol in conjunction with a progestin, estrus behavior, the pre-ovulatory LH surge, or ovulation does not occur; however, regression of the DF will transpire. The mechanism of follicle regression following estradiol administration appears to be systemic rather than local. Injecting estradiol-17 beta directly into the ovarian stroma, did not induce regression of the DF (Bo et al., 2000). However, injecting estradiol i.m. and in the wall of the uterus ipsilateral to the DF induced regression of the DF and emergence of a new follicular wave.

The systemic effect of estradiol on follicular development has been attributed to gonadotropin suppression. Bo et al. (1994) reported decreased circulating FSH concentrations following administration of estradiol-17 beta when animals had been fitted with a norgestomet implant. The combination of an estrogen and progestin has been shown to suppress both mean concentrations of LH and FSH (Price and Webb, 1988). Barnes et al. (1981) reported mean plasma FSH of cows treated with a norgestomet implant (9-d duration), in conjunction with an injection of estradiol valerate at implant insertion, was depressed for a period of $96 \mathrm{~h}$ following treatment initiation. In addition, plasma LH remained low throughout treatment. By administering estradiol in 
conjunction with progesterone, the resulting suppression of FSH and LH causes regression of both subordinate and dominant follicles and emergence of a new follicular wave.

\section{Chapter 3. Rationale and Experimental Objectives}

Synchronizing development of the DF at the beginning of a progestin treatment to synchronize estrus, leads to acceptable estrus responses and conception rates. Two experimental tools exist to restart follicular development at the beginning of a progestin treatment, estrogens and GnRH. The timing and mechanisms controlling emergence of a follicular wave following treatment with estrogens or GnRH are quite different. Therefore, before the most effective progestin-based synchronization system can be devised, it is necessary to determine the optimal duration of progestin treatment and relative timing of exogenous estrogen or $\mathrm{GnRH}$ administration to control follicular development.

Varying the interval from follicle emergence to CIDR removal may create differences in DF size at CIDR removal. Differences in size of the DF may lead to considerable variation in the timing and synchrony of estrus following CIDR removal. The objectives of this experiment were to investigate the effects of varying the interval from follicle emergence to progestin withdrawal on follicular dynamics and the synchrony of estrus and ovulation following treatment with a progestin and either GnRH or estradiol-17 beta and progesterone. In addition, the effects of developing a follicle in the presence or absence of a functional CL during the progestin-based estrous synchronization treatment was investigated. 


\section{Chapter 4. Materials and Methods}

\section{Pretreatment Synchronization}

Prior to administration of experimental treatments, estrus was synchronized in mature, non-lactating Angus cows with an injection of GnRH (Cystorelin, 100 mcg, i.m., Merial, Iselin, NJ) followed by an injection of PG (Lutalyse, 25 mg, i.m., PharmaciaUpjohn, Kalamazoo, MI) 7 d later. Cows were observed twice-daily for signs of behavioral estrus after PG administration. Six to eight days after estrus detection, cows were examined, via transrectal ultrasonography, to verify the presence of a CL and to record the location of the DF. Each cow with a functional CL was randomly assigned to one of eight experimental treatments. The experiment was conducted in two replicates $(n=22$ and $n=27)$. Forty-nine estrus periods were detected across both replicates. Six cows were used in both replicates; however, each estrous cycle was treated as an independent event.

\section{Experimental Treatments}

The experiment was designed as a $2 \times 2 \times 2$ factorial with duration of exogenous progestin treatment, in the presence or absence of a CL, and method of controlling follicular wave emergence as main effects (Fig 4.1). Six to eight days after detection of estrus, each cow was fitted with an intravaginal controlled internal drug-releasing device (CIDR-B, Vetrepharm Canada Inc., Ontario Canada), containing $1.9 \mathrm{~g}$ of progesterone for $7(n=26)$ or $9 d(n=23)$. One half of the cows in each CIDR treatment group received an injection of $\mathrm{E}_{2}$ (estradiol-17 beta, $1 \mathrm{mg}$, i.m.) and $\mathrm{P}_{4}$ (progesterone, $100 \mathrm{mg}$, i.m.) in vegetable oil at the time of CIDR insertion. The remaining half received an injection of GnRH. The presence or absence of a CL throughout the period of exogenous progestin treatment was controlled by administering saline or a series of luteolytic injections of PG at the beginning of the CIDR treatment. One half of the cows administered the $\mathrm{E}_{2}+\mathrm{P}_{4}$ (subgroups $\mathrm{A}$ and $\mathrm{C}$ ) and one half of the cows administered GnRH (subgroups B and D) treatments received three injections of saline $12 \mathrm{~h}$ apart beginning at the time of CIDR insertion. The other half of the animals in each group received three injections of PG (12.5 mg each) at 12-h intervals beginning at the time of 


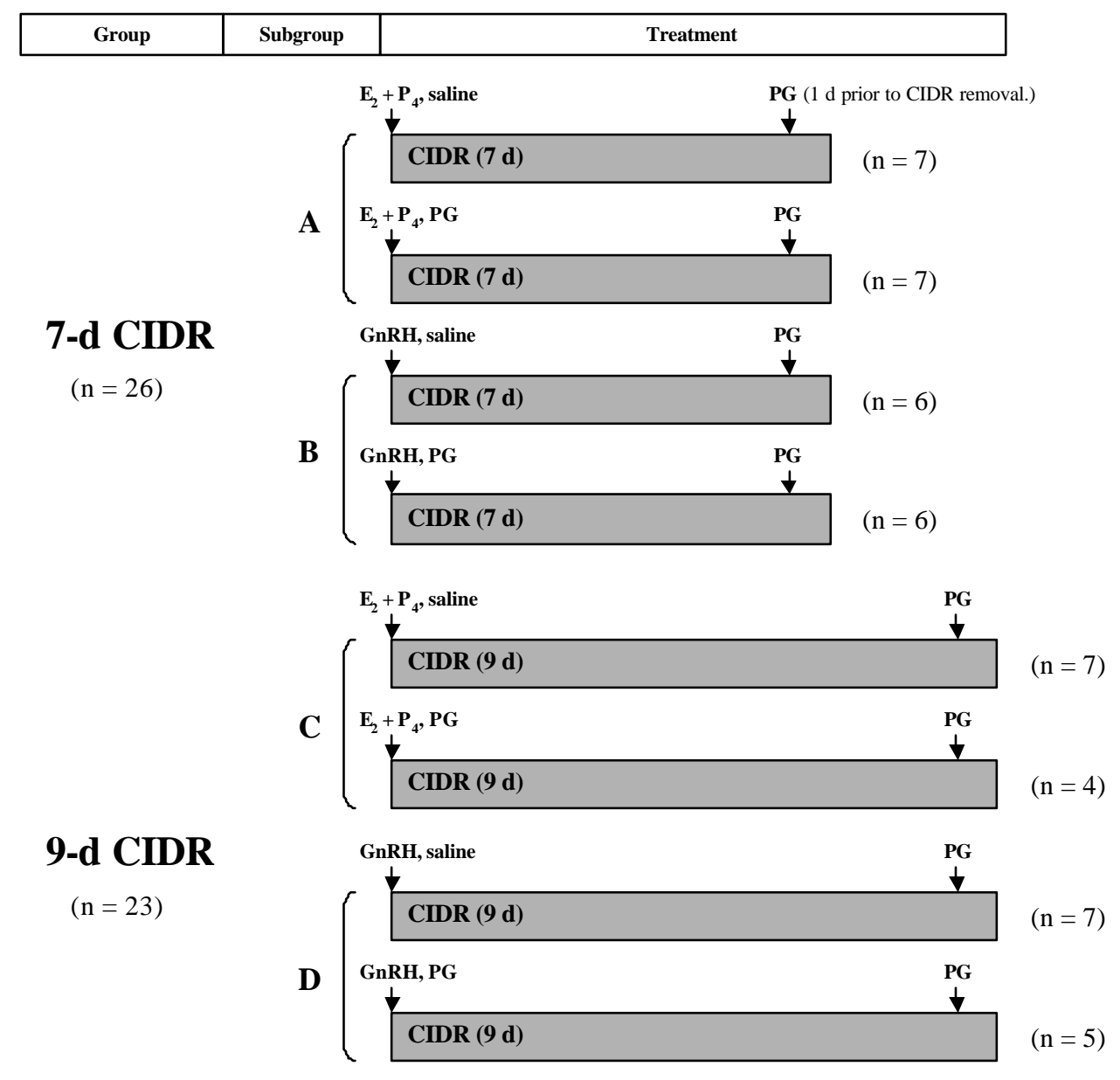

Figure 4.1. Diagram of experimental treatments with 7 or $9 \mathrm{~d}$ CIDR, GnRH or estradiol-17 beta, and PG or saline as main effects.

CIDR insertion. One day prior to CIDR removal, all cows in each group received a single injection of PG (25 mg, i.m.). At the time of CIDR removal, cows were fitted with an electronic device (HeatWatch, DDX, Inc., Denver, CO) to detect standing events associated with the onset of estrus. HeatWatch transmitters remained on animals until ovulation at which time they were removed. During the experiment, three animals lost electronic transmitters after the onset of estrus was detected but prior to ovulation and these animals were not included in data of estrus period characteristics.

\section{Ultrasound Examinations}

Beginning at the time of CIDR insertion, transrectal ultrasonography was performed once-daily using a B-mode ultrasound machine (Sonovet 600, Universal 
Medical Systems, Inc., Bedford Hills, NY) equipped with a 7.5 MHz linear-array transducer. Daily recording of ovarian ultrasonography continued until the day that each animal exhibited behavioral estrus. Ultrasound observations were recorded on VHS videocassette and were later reviewed to characterize follicular development. Follicle size was determined by the measuring the largest diameter of the follicle. Emergence of a follicular wave was defined as the presence of a pool of follicles, $\geq 3 \mathrm{~mm}$ in diameter, following estradiol or GnRH treatment. Deviation of the dominant follicle was defined as the time the second largest follicle present on the ovary reached its maximum diameter (Ginther et al., 1996). The growth rate of the DF follicle was calculated from the daily ultrasound observations beginning at treatment initiation and ending at estrus.

Ultrasonography was also used to determine the interval from the onset of estrus to ovulation. Ultrasound examinations commenced $24 \mathrm{~h}$ after the onset of estrus and were performed at 3-h intervals until ovulation. Time of ovulation was determined as the average time between the last observation that the DF was present and the time at which the DF had disappeared.

\section{Blood Collection and Progesterone RIA}

Blood samples were collected once-daily via tail venipuncture beginning at the time of CIDR insertion and ending the day the animal displayed behavioral estrus. Samples were allowed to stand at room temperature for $6 \mathrm{~h}$. Serum was separated by centrifugation at $1678 \mathrm{~g}$ for $20 \mathrm{~min}$, and samples were frozen and stored at -20 degrees Celsius. A validated (Holt et al., 1989), solid-phase RIA procedure (Coat-A-Count, Diagnostic Products) was used to determine serum progesterone concentrations. Samples were analyzed in duplicate in a single assay. The minimal detectable limit of progesterone for the assay was $0.02 \mathrm{ng} / \mathrm{mL}$. The intra-assay coefficient of variation was $9 \%$.

\section{Statistical Analysis}

The design used in this experiment was a $2 \times 2 \times 2$ factorial with duration of CIDR treatment, $\mathrm{E}_{2}+\mathrm{P}_{4}$ or GnRH treatment, and $\mathrm{PG}$ or saline treatment at the time of CIDR insertion as main effects. Because no effect of replicate existed, data from both replicates were combined and analyzed with the following procedures. Dependent variables were analyzed by ANOVA in the GLM procedure of SAS. Main effects and 
interactions analyzed in the model that were not significant were removed from the statistical model. When significant differences were detected, least-squares analysis was performed to identify differences in means. Means and least-square means are depicted \pm SE unless otherwise stated.

Characteristics of follicular waves and size of the DF at the time of CIDR removal, the time of estrus, or the time of ovulation were analyzed using ANOVA with the model and procedures stated above. Growth rate of the DF was calculated using simple linear regression with day as the independent variable and follicle size as the dependent variable. Differences in growth rate were analyzed using ANOVA as described above.

Data collected from the HeatWatch system were used to determine the interval from CIDR removal to the onset of estrus (time of first mount) and the duration and intensity (number of mounts received by each cow) of estrus. The interval from CIDR removal to the onset of estrus, the duration of estrus, and the intensity of estrus were analyzed using ANOVA in the GLM procedure of SAS. Differences among main effects in the intensity of estrus were detected using ANOVA with the duration of estrus as a covariate. The variance for the interval from CIDR removal to estrus was used as a measure of the synchrony of estrus following treatment. Differences due to main effects in variance associated with the interval from CIDR removal to estrus were analyzed using the F-test (Steele and Torrie, 1960).

Serum progesterone levels were analyzed at 0,1 , and $5 \mathrm{~d}$ following CIDR insertion and at estrus using ANOVA in the GLM procedure of SAS. A repeatedmeasures analysis in the mixed model procedure of SAS was performed to detect differences in serum progesterone concentrations during the first $6 \mathrm{~d}$ of the experimental treatment. Cows treated with PG or saline at CIDR insertion were analyzed separately from one another, and the effect of $\mathrm{GnRH}$ or $\mathrm{E}_{2}+\mathrm{P}_{4}$ on serum progesterone during the first $6 \mathrm{~d}$ of treatment were analyzed for cows treated in each group (PG or saline). Fixed effects of the model included main effects, day, and a main effect by day interaction. Individual cows were treated as random effects in the model. 


\section{Chapter 5. Results}

Experimental data was collected from 49 cycling Angus cows assigned to one of eight experimental treatments. The experiment was designed as a $2 \times 2 \times 2$ factorial and all data, except for analysis of serum progesterone concentrations were analyzed using this model (see below). There were no significant two- or three-way interactions among main effects for any of the dependent variables. Therefore, experimental data were analyzed for the following main effects only: treatment with $\mathrm{E}_{2}+\mathrm{P}_{4}(\mathrm{n}=25)$ or $\mathrm{GnRH}(\mathrm{n}=24)$ at CIDR insertion, administration of PG $(n=24)$ or saline $(n=25)$ at CIDR insertion, and treatment with a CIDR for a period of $7(n=26)$ or $9 d(n=23)$.

\section{Follicular Development}

Follicular events were characterized using recordings of daily ultrasound observations beginning at the time of CIDR insertion and ending at estrus. Least-square means $(\mathrm{LSM} \pm \mathrm{SE})$ of characteristics of the follicular wave and DF are contained in Table 5.1. Treating cows with either $\mathrm{E}_{2}+\mathrm{P}_{4}$ or $\mathrm{GnRH}$ induced the emergence of a new follicular wave; however, the interval from treatment to follicular wave emergence was significantly different between the two treatments. Cows treated with $\mathrm{E}_{2}+\mathrm{P}_{4}$ at CIDR insertion exhibited a longer interval from $\mathrm{E}_{2}+\mathrm{P}_{4}$ treatment $(3.3 \mathrm{~d})$ to follicular wave emergence than those treated with GnRH at CIDR insertion $(1.4 \mathrm{~d}, \mathrm{P}<0.05)$. The emergence of a new wave of follicles occurred across a range of 0 to $2 \mathrm{~d}$ following $\mathrm{GnRH}$ treatment. Conversely, timing of emergence of a follicular wave following $\mathrm{E}_{2}+\mathrm{P}_{4}$ treatment ranged from 1 to $7 \mathrm{~d}$.

Because a new follicular wave emerged more quickly following GnRH treatment, the interval from follicular wave emergence to CIDR removal was greater in cows treated with $\mathrm{GnRH}$ at CIDR insertion compared to those treated with $\mathrm{E}_{2}+\mathrm{P}_{4}(\mathrm{P}<0.05)$. Likewise, the interval from follicular wave emergence to CIDR removal was significantly greater in animals that received a CIDR for 9 rather than $7 \mathrm{~d}$.

One specific aim of this experiment was to administer treatments that altered the interval from emergence of a follicular wave until progestin removal and the onset of a

synchronized estrus. This was accomplished in two ways, by administering either $\mathrm{E}_{2}+\mathrm{P}_{4}$ 
or GnRH at treatment initiation and by treating animals with a CIDR for a duration of 7 or $9 \mathrm{~d}$. Administration of $\mathrm{E}_{2}+\mathrm{P}_{4}$ or $\mathrm{GnRH}$ caused emergence of a new wave of follicles to

Table 5.1. Main effects of estradiol-17 beta or GnRH administration, 7 or 9-d CIDR treatment, or PG or saline treatment on characteristics of the dominant follicle (DF).

\begin{tabular}{|c|c|c|c|c|c|c|c|}
\hline \multirow[b]{2}{*}{ Item } & \multicolumn{7}{|c|}{ Main Effects" } \\
\hline & $\begin{array}{l}\mathbf{E}_{2}+\mathbf{P}_{4} \\
(\mathrm{n}=25)\end{array}$ & $\begin{array}{l}\text { GnRH } \\
(\mathrm{n}=24)\end{array}$ & $\begin{array}{l}\text { CIDR } 7 \\
(\mathrm{n}=26)\end{array}$ & $\begin{array}{l}\text { CIDR 9 } \\
(\mathrm{n}=23)\end{array}$ & $\begin{array}{c}\text { PG } \\
(\mathrm{n}=24)\end{array}$ & $\begin{array}{l}\text { Saline } \\
(\mathrm{n}=25)\end{array}$ & $\begin{array}{l}\text { Pooled } \\
\text { SE }\end{array}$ \\
\hline $\begin{array}{l}\text { Interval from initiation of } \\
\text { treatment to emergence (d) }\end{array}$ & $3.3^{\mathrm{a}}$ & $1.4^{\mathrm{b}}$ & 2.2 & 2.5 & 2.2 & 2.5 & 0.2 \\
\hline $\begin{array}{l}\text { Interval from emergence to } \\
\text { CIDR removal (d) }\end{array}$ & $4.7^{\mathrm{a}}$ & $6.6^{\mathrm{b}}$ & $4.8^{\mathrm{a}}$ & $6.5^{\mathrm{b}}$ & 5.8 & 5.5 & 0.2 \\
\hline DF Growth Rate (mm/d) & $1.5^{\mathrm{c}}$ & $1.3^{\mathrm{d}}$ & $1.5^{\mathrm{a}}$ & $1.2^{\mathrm{b}}$ & $1.5^{\mathrm{a}}$ & $1.3^{\mathrm{b}}$ & 0.06 \\
\hline \multicolumn{8}{|l|}{ DF size $(\mathrm{mm})$ at: } \\
\hline CIDR removal & $11.3^{\mathrm{a}}$ & $13.4^{\mathrm{b}}$ & $11.8^{\mathrm{c}}$ & $13.0^{\mathrm{d}}$ & $13.2^{\mathrm{a}}$ & $11.5^{\mathrm{b}}$ & 0.4 \\
\hline Estrus & $14.3^{\mathrm{a}}$ & $16.0^{\mathrm{b}}$ & 14.9 & 15.4 & $15.8^{\mathrm{a}}$ & $14.5^{\mathrm{b}}$ & 0.4 \\
\hline Ovulation & $15.6^{\mathrm{c}}$ & $16.6^{\mathrm{d}}$ & 15.8 & 16.4 & $17.0^{\mathrm{a}}$ & $15.3^{\mathrm{b}}$ & 0.4 \\
\hline
\end{tabular}

* Least-square means.

${ }^{\mathrm{a}, \mathrm{b}}$ Least-square means within each row and main effect with uncommon superscripts differ $(\mathrm{P}<0.05)$.

${ }^{\mathrm{c}, \mathrm{d}}$ Least-square means within each row and main effect with uncommon superscripts $\operatorname{differ}(\mathrm{P}<0.07)$.

occur 3.3 or $1.4 \mathrm{~d}$ following treatment and treatment with a CIDR for 7 or $9 \mathrm{~d}$ altered the interval from emergence to CIDR removal by approximately $2 \mathrm{~d}$. The combined effect of administering different treatments to cause emergence of a new wave and allowing CIDRs to remain in place for varying durations, led to a range in the interval from follicular wave emergence to CIDR removal from 2 to $9 \mathrm{~d}$. Varying the interval from follicular wave emergence to CIDR removal influenced the characteristics of the DF that was present at the time of estrus and that ovulated following the synchronized estrus.

The size of the DF at CIDR removal was altered by administration of PG or saline at CIDR insertion. The size of the DF at CIDR removal was larger in cows treated with $\mathrm{PG}$ at CIDR insertion than saline $(\mathrm{P}<0.05)$. The larger size attained by the DF of cows treated with PG was due to an increased growth rate of the DF associated with animals treated with PG compared to those treated with saline. The DF of animals treated with 
PG at CIDR insertion had a more rapid growth rate $(1.5 \mathrm{~mm} / \mathrm{d})$ than those treated with saline $(1.3 \mathrm{~mm} / \mathrm{d})(\mathrm{P}<0.05)$. Differences in the size of the DF at CIDR removal, created by administration of PG or saline at CIDR insertion, led to differences in the size of the $\mathrm{DF}$ at estrus and ovulation. The DF of cows treated with PG at CIDR insertion was larger at the time of both estrus and ovulation compared to the DF of animals treated with saline $(\mathrm{P}<0.05)$.

Like cows treated with PG at CIDR insertion, the DF of those that received GnRH at CIDR insertion had attained a larger diameter by the time of CIDR removal compared to those treated with $\mathrm{E}_{2}+\mathrm{P}_{4}(\mathrm{P}<0.05)$. Consequently, cows treated with GnRH maintained a larger DF at estrus and ovulation compared to those treated with $\mathrm{E}_{2}+\mathrm{P}_{4}$ $(\mathrm{P}<0.07)$. Similar to cows treated with GnRH, the size of DF of cows treated with a CIDR for $9 \mathrm{~d}$ tended to be larger at the time of CIDR removal compared to cows treated with a CIDR for $7 \mathrm{~d}(\mathrm{P}<0.07)$. However, no differences or trends in the size of the DF at estrus or ovulation existed between cows treated with a CIDR for 7 or $9 \mathrm{~d}$.

Despite differences in the interval from $\mathrm{E}_{2}+\mathrm{P}_{4}$ or $\mathrm{GnRH}$ treatment to follicular wave emergence and differences in DF size, there was no difference in the interval from follicular wave emergence to deviation of the DF across all experimental treatments. Hence, irrespective of the method used to induce emergence of a new wave, the timing of deviation was a consistent event relative to follicular wave emergence. The mean interval from follicular wave emergence to deviation, across all experimental treatments, was $3.1 \pm 0.1 \mathrm{~d}$.

Characteristics of the new follicular wave, which resulted from $\mathrm{E}_{2}+\mathrm{P}_{4}$ or $\mathrm{GnRH}$ treatment, are depicted in Figures 5.1 and 5.2. Means $( \pm S D)$ of follicle diameter, for both dominant and subordinate follicles, were calculated for each day of experimental treatment beginning at treatment initiation. Emergence of subordinate follicles was standardized to the time of $\mathrm{DF}$ emergence following $\mathrm{GnRH}$ or $\mathrm{E}_{2}+\mathrm{P}_{4}$ treatment. If the data set was not complete for all cows on a given day, then the mean for that day was not included and the line of the graph was terminated at that point. In two cows, the DF present at the start of treatments did not ovulate following GnRH injection; however, emergence of a new follicular wave occurred. These cows were excluded from the means $( \pm \mathrm{SD})$ of GnRH treated animals in Figures 5.1 and 5.2. 

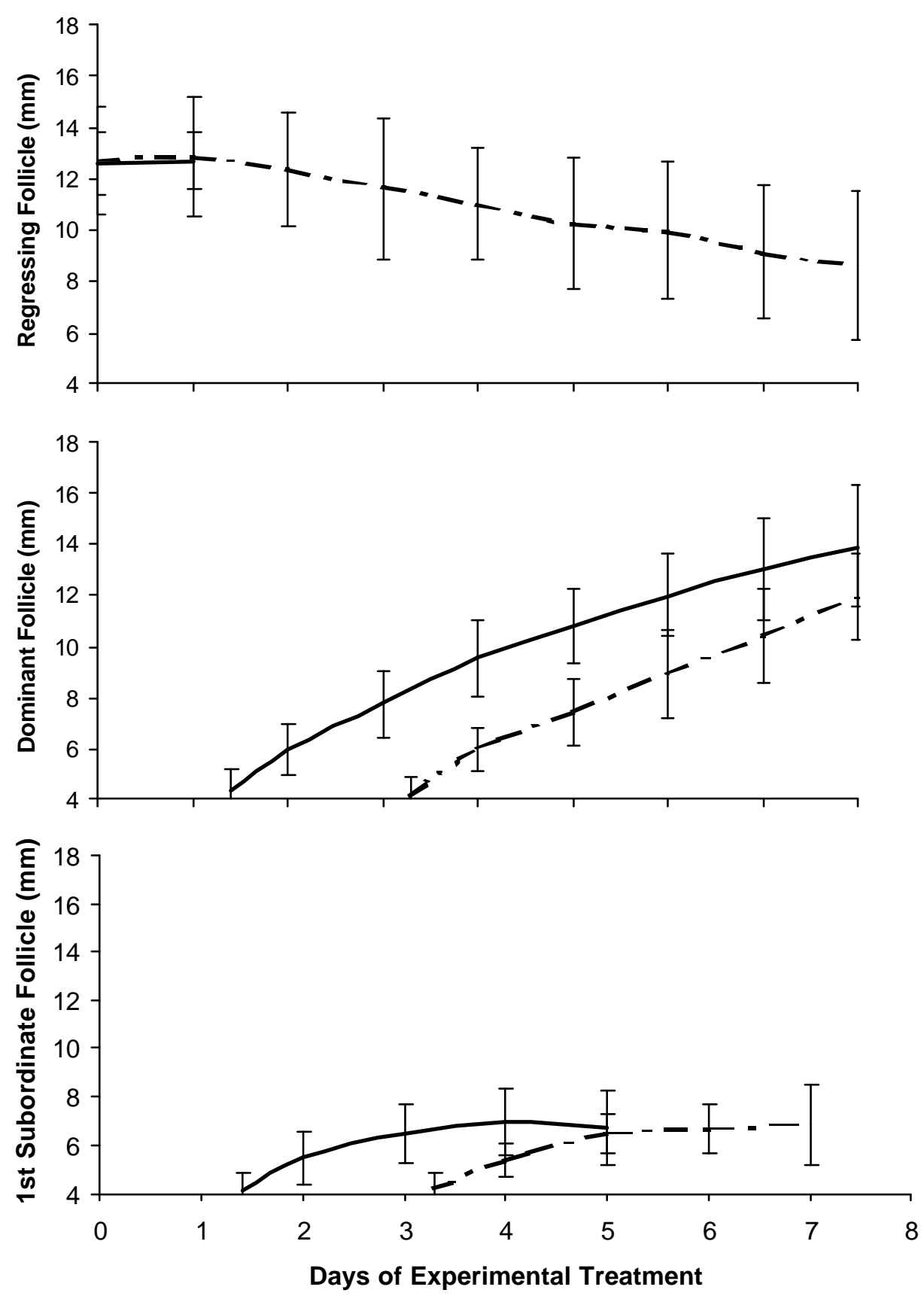

Figure 5.1. Means $( \pm \mathrm{SD})$ of follicle diameter of cows treated with estradiol-17 beta and progesterone (-..-) or GnRH (-) at CIDR insertion plotted by day of experimental treatment and normalized within treatment group to the time of dominant follicle emergence. 


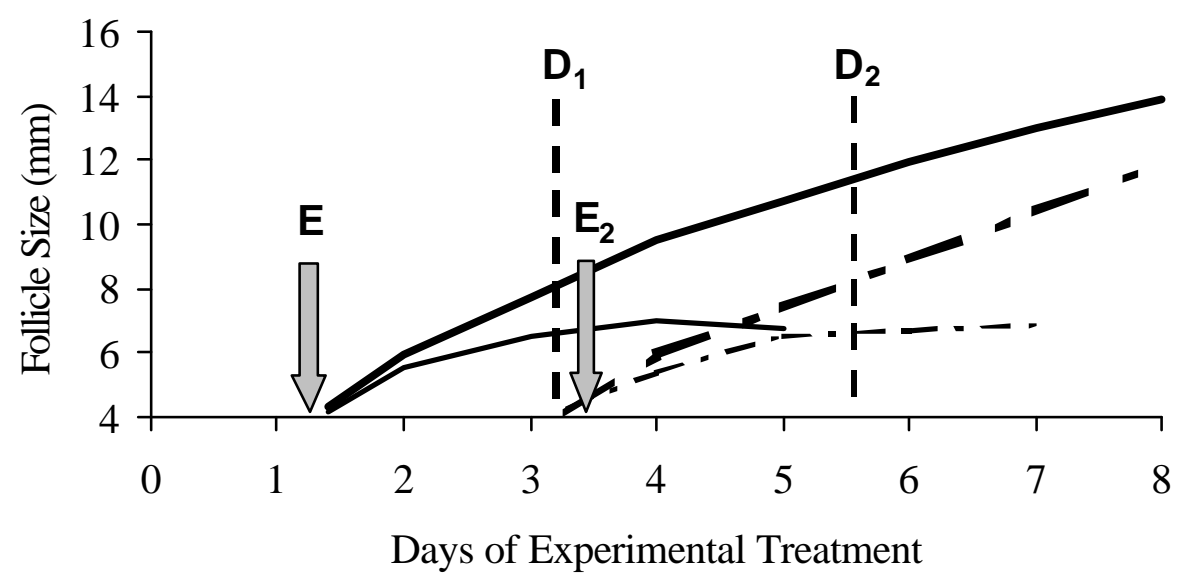

Figure 5.2. Means of follicle diameter for the dominant (dark line) and first subordinate follicle plotted by day of experimental treatment, time of follicular wave emergence $(\mathbf{E})$, and time of dominant follicle deviation $(\mathbf{D})$ for cows treated with 1) estradiol-17 beta and progesterone (-..-) or 2) $\mathrm{GnRH}(\longrightarrow$ at the time of CIDR insertion.

\section{Timing and Synchrony of Estrus}

Estrus activity was monitored via HeatWatch, an electronic estrus detection system. Data from HeatWatch were used to determine the timing of the onset of estrus, duration of estrus, and the number of standing events for each cow. Least-square mean intervals from CIDR removal to the onset of estrus are shown in Figure 5.3. Despite differences created in the interval from follicular wave emergence to CIDR removal, no differences existed in the interval from CIDR removal to the onset of estrus between animals treated with $\mathrm{GnRH}$ or $\mathrm{E}_{2}+\mathrm{P}_{4}$ at $\mathrm{CIDR}$ insertion or between animals that received treatment with a CIDR for a duration of 7 or $9 \mathrm{~d}$. However, cows treated with PG at CIDR insertion exhibited a shorter interval from CIDR removal to the onset of estrus than those cows treated with saline $(\mathrm{P}<0.05)$. Although no differences in the interval from CIDR removal to estrus existed for other experimental treatments, a trend existed between the size of the DF at CIDR removal and the interval from CIDR removal to the onset of estrus in all animals. Plotted in Figure 5.4 is the regression of size of the DF at 
CIDR removal on the interval from CIDR removal to the onset of estrus. An increase in the size of the DF at CIDR removal appeared to lead to a decrease in the interval from CIDR removal to the onset of estrus. Although differences existed in the interval from

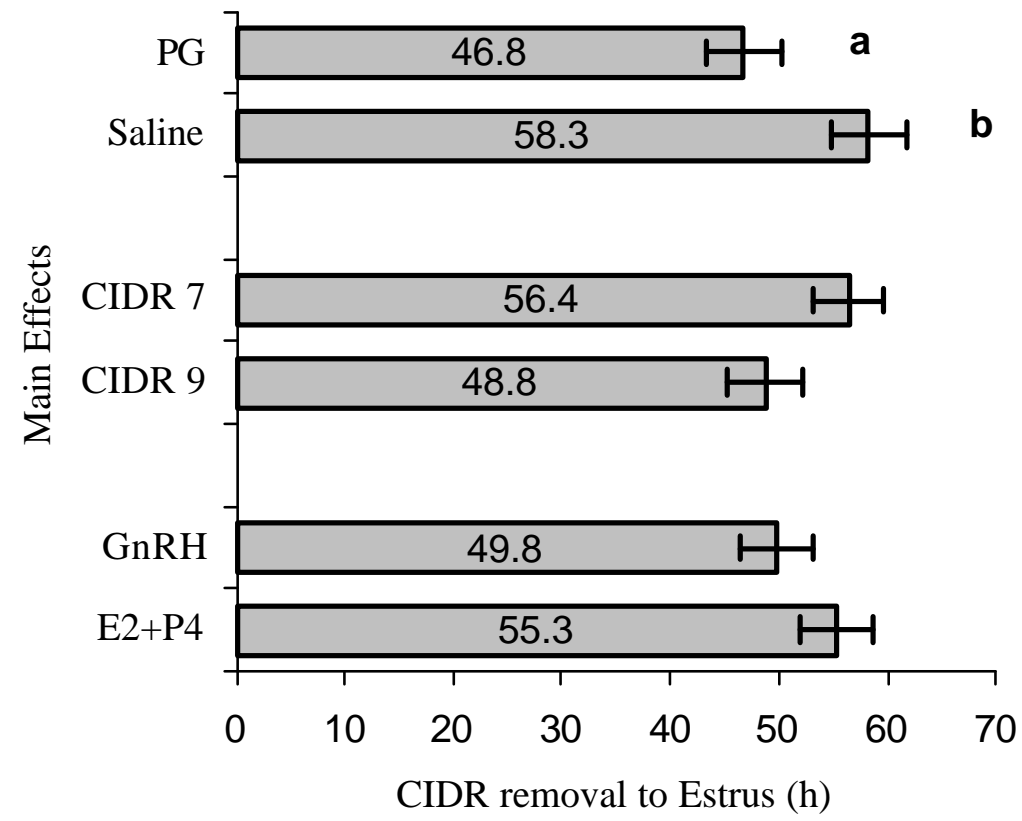

Figure 5.3. The interval (LSM $\pm \mathrm{SE}$ ) from CIDR removal to estrus for cows treated with estradiol-17 beta and progesterone or GnRH at CIDR insertion, CIDR treatment duration of 7 or $9 \mathrm{~d}$, and PG or saline at CIDR insertion. ${ }^{\mathrm{a}, \mathrm{b}} \mathrm{LSM}$ differ $(\mathrm{P}<$ $0.05)$.

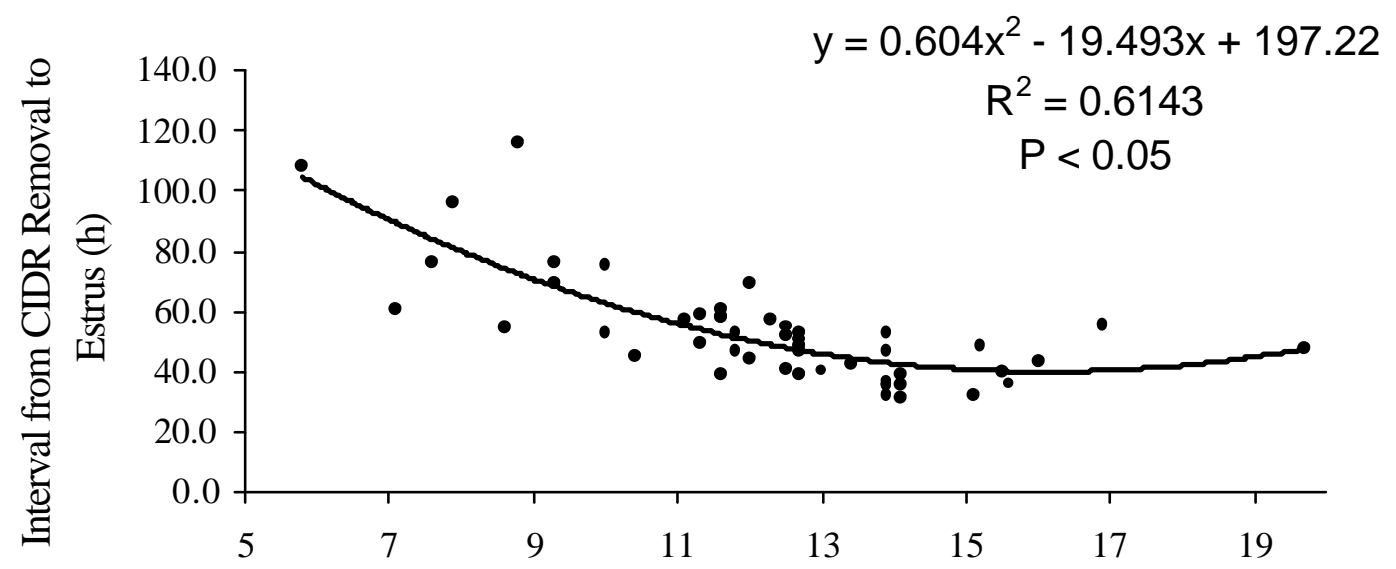

Follicle Diameter at CIDR Removal (mm)

Figure 5.4. The regression of diameter of the dominant follicle at CIDR removal on the interval from CIDR removal to the onset of estrus showing the relationship between size of the DF at CIDR removal and the interval to the onset of estrus. 
CIDR removal to the onset of estrus between cows treated with PG or saline at CIDR insertion, no differences in the synchrony of estrus were found across all treatments. Figure 5.5 illustrates the synchrony of estrus (variation around the mean interval from CIDR removal to estrus) for experimental treatments.

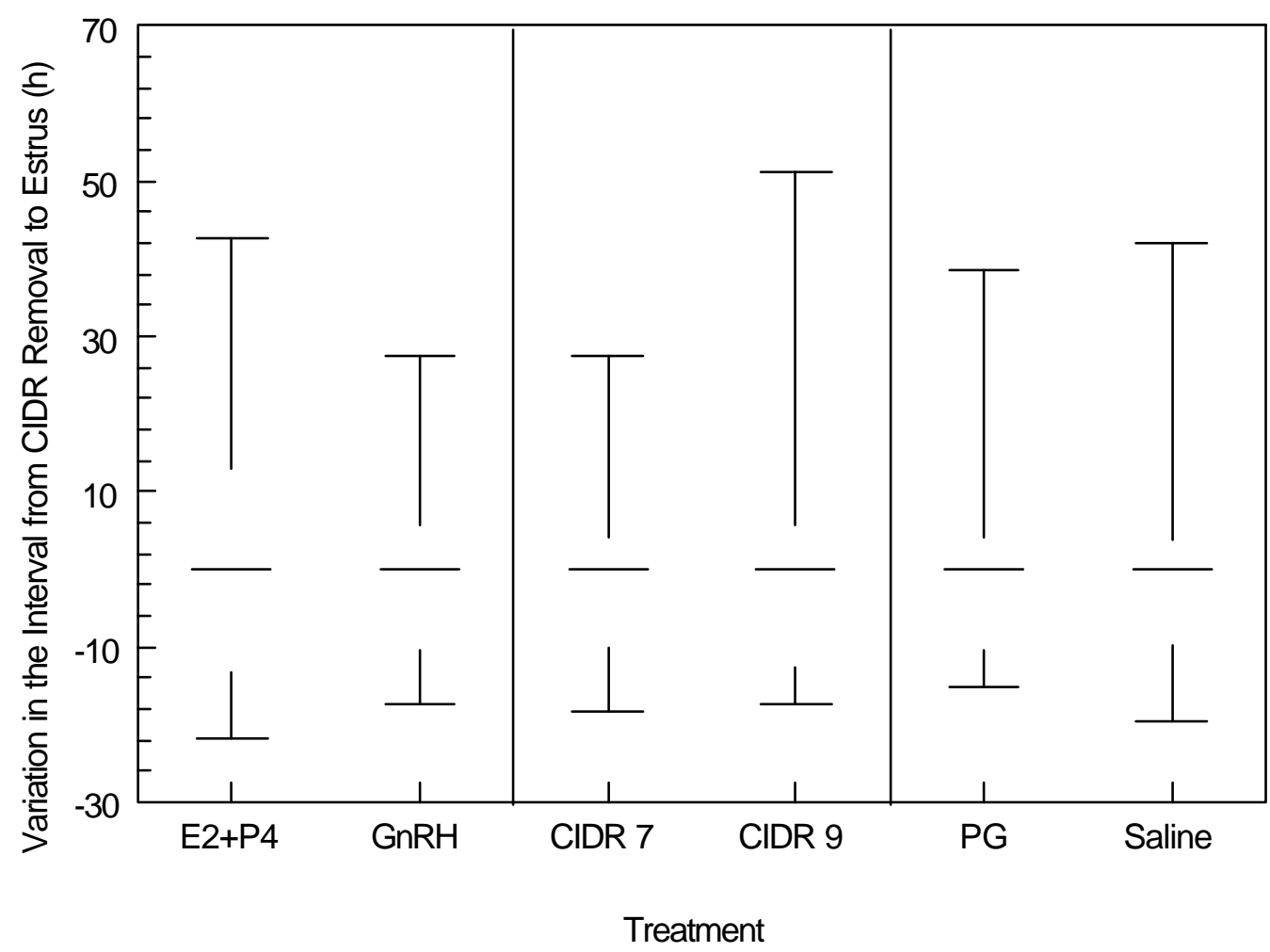

Figure 5.5. The variation in the interval from CIDR removal to estrus (synchrony of estrus) with the mean interval from CIDR removal to estrus normalized to $0 \mathrm{~h}$. Variation between main effects did not differ (E2+P4 vs. GnRH; CIDR 7 vs. CIDR 9; PG vs. Saline; $\mathrm{P}>0.05$ )

The interval from the onset of estrus to ovulation was determined by ultrasound observations commencing $20 \mathrm{~h}$ after the onset of estrus and continued every $3 \mathrm{~h}$ until disappearance of the largest follicle present on the ovary at estrus. The interval from the onset of estrus to ovulation was not different between treatments. The mean $( \pm$ SD) interval from the onset of estrus to ovulation across all treatments was $32.0 \pm 4.4 \mathrm{~h}$. 
In addition to the intervals from CIDR removal to the onset of estrus and the onset of estrus to ovulation, the duration and intensity (number of standing events) of estrus were also recorded from data generated by the HeatWatch system. The duration of estrus ranged from 4.2 to $26.7 \mathrm{~h}$ among animals in the experiment. The mean duration of estrus was $15.3 \pm 0.63 \mathrm{~h}$ and was not different among treatment groups. The number of standing events $\left(\mathrm{LSM}_{\mathbf{E}} \mathrm{SE}\right)$ for animals in each treatment group are contained in Figure 5.6. The number of standing events for cows across all treatments ranged from 5 to 79 . The mean number of standing events for all cows was $36.5 \pm 2.89$. Neither duration of CIDR treatment nor administration of PG or saline at CIDR insertion influenced the number of standing events recorded for the duration of estrus. However, cows treated with $\mathrm{E}_{2}+\mathrm{P}_{4}$ at CIDR insertion exhibited fewer standing events than those treated with GnRH at CIDR insertion $(\mathrm{P}<0.01)$.

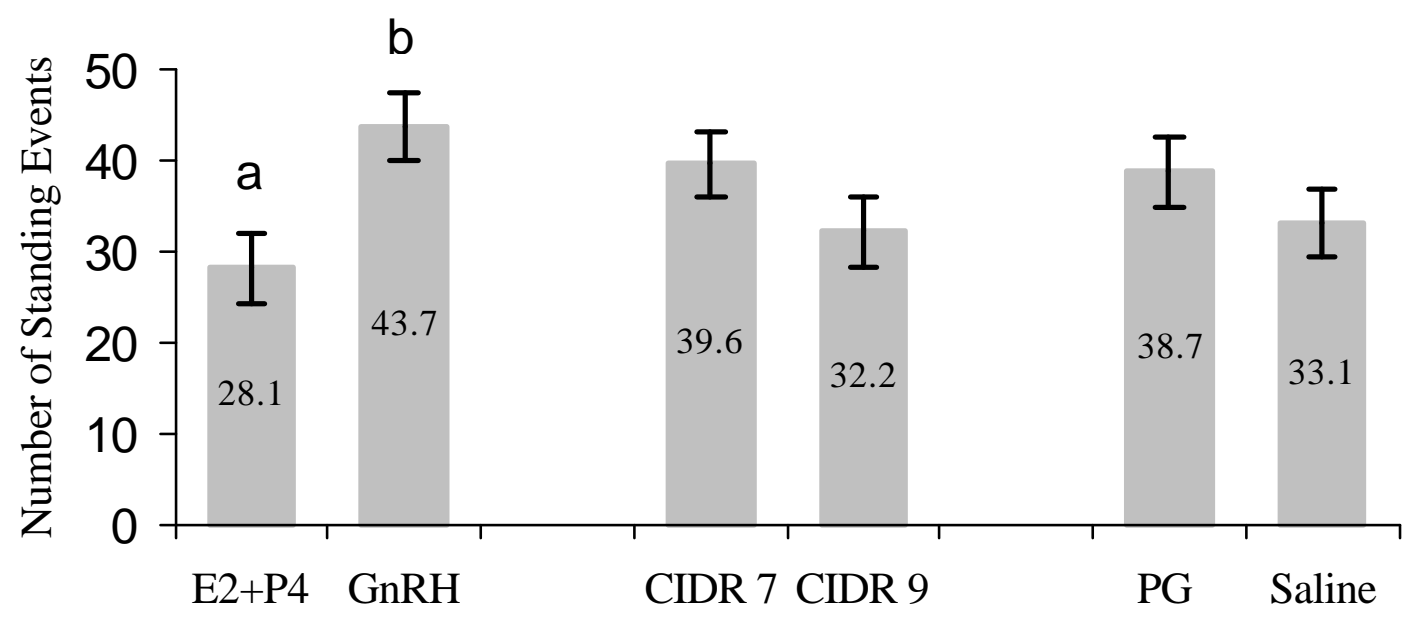

Figure 5.6. Number of standing events $(\mathrm{LSM} \pm \mathrm{SE})$ received during estrus for cows treated with estradiol-17 beta (E2+P4) and progesterone or GnRH, 7- or 9-d duration of CIDR treatment, or PG or saline administration at CIDR insertion. ${ }^{\mathrm{a}, \mathrm{b}} \mathrm{LSM}$ differ $(\mathrm{P}<0.01)$.

\section{Luteal Structures}

The presence or absence of the CL was controlled by administering saline or PG at CIDR insertion. Prior to administering experimental treatments, cows were examined via trans-rectal ultrasonography to verify the presence of a CL (primary CL). If a CL was present at the time of ultrasound examination, cows were randomly assigned to one of the eight experimental treatments. The corpora lutea of cows that received saline at CIDR 
insertion were maintained until PG administration $1 \mathrm{~d}$ prior to CIDR removal. In contrast, the corpora lutea of cows that received PG at CIDR insertion all showed evidence of regression.

Administration of GnRH at CIDR insertion luteinized the DF present on the ovary at the beginning of experimental treatments. The luteinization of the DF led to development of an additional CL. The majority of cows (22/24) that received GnRH at CIDR insertion developed a secondary CL. Cows that received GnRH and saline at CIDR insertion maintained the primary CL in addition to development of a secondary CL due to GnRH administration. However, in cows that received GnRH and PG at CIDR insertion, the primary CL regressed, but formation of a secondary CL occurred. The presence of the secondary CL was readily detectable with ultrasonography on average $4.1 \mathrm{~d}$ following GnRH treatment. The presence of a secondary CL during the first $6 \mathrm{~d}$ of experimental treatment did not alter serum progesterone concentrations $(\mathrm{P}>0.05)$. The serum progesterone concentrations for cows treated with $\mathrm{GnRH}$ or $\mathrm{E}_{2}+\mathrm{P}_{4}$ and $\mathrm{PG}$ or saline at CIDR insertion are contained in Figure 5.7. The increased serum progesterone concentrations during the first $2 \mathrm{~d}$ of experimental treatment in cows treated with $\mathrm{E}_{2}+\mathrm{P}_{4}$ was due to the $100 \mathrm{mg}$ of progesterone administered in the $\mathrm{E}_{2}+\mathrm{P}_{4}$ treatment.

\section{Serum Progesterone}

One of the specific goals of this experiment was to alter the progesterone environments in which the newly emerged follicular waves developed and to examine this effect on the development of the DF. Administering PG at CIDR insertion caused regression of the CL present at treatment initiation; thus, decreasing serum progesterone levels during CIDR treatment.

Blood samples, taken at 0,1 , and $5 \mathrm{~d}$ following CIDR insertion and at estrus, were analyzed for serum progesterone concentrations to verify that different levels of progesterone were created during the experimental treatment by controlling the presence or absence of the primary CL. Figure 5.8 depicts serum progesterone concentrations of cows treated with PG or saline at CIDR insertion at 0,1 , and $5 \mathrm{~d}$ following treatment initiation and at estrus. Administration of PG or saline at CIDR insertion significantly affected circulating progesterone levels during the period of CIDR treatment. Cows 

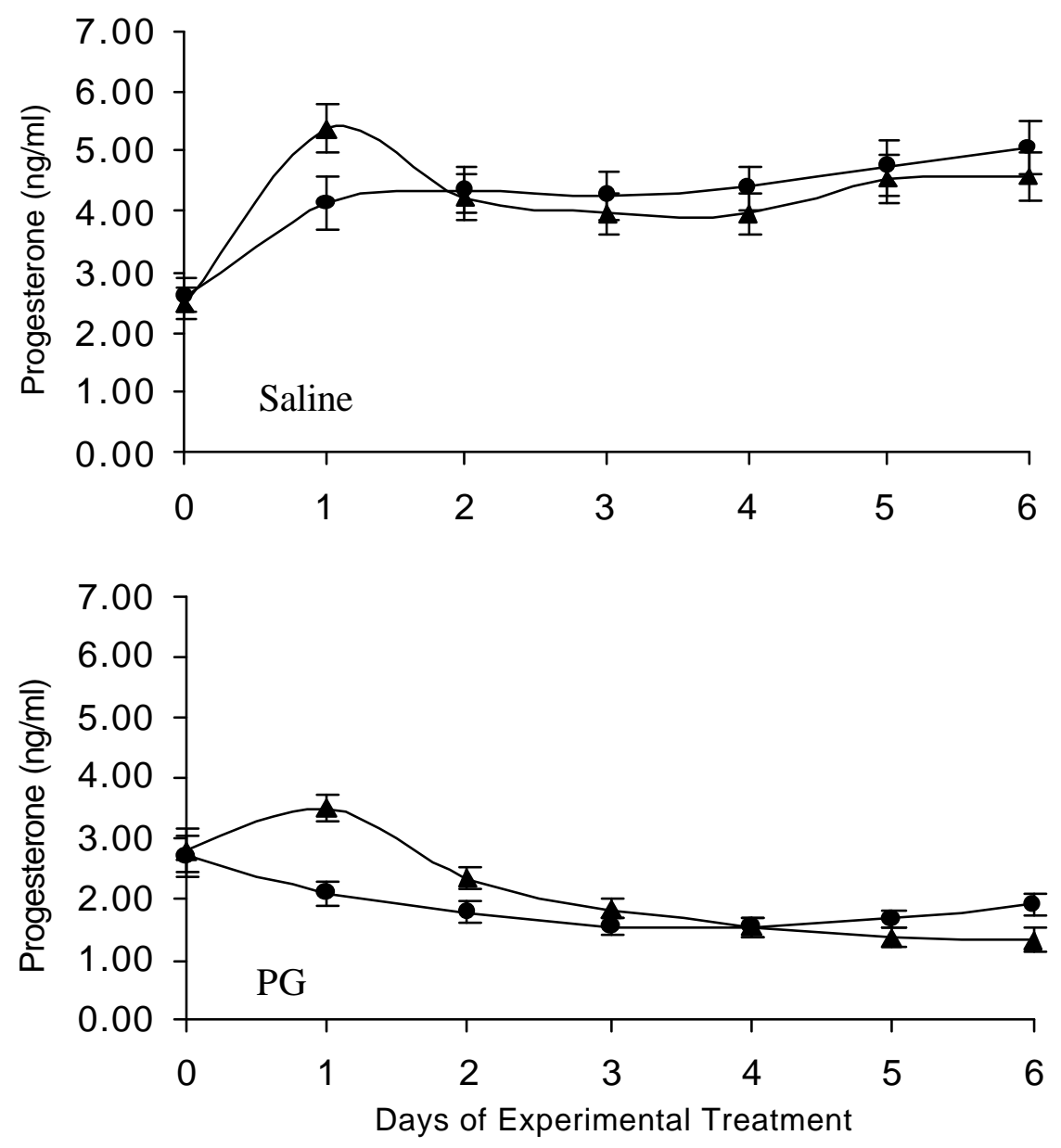

Figure 5.7. Serum progesterone concentrations $(\mathrm{LSM} \pm \mathrm{SE})$ of cows treated with estradiol-17 beta (__ ) and progesterone or $\mathrm{GnRH}(\longrightarrow-\square)$ during the first $6 \mathrm{~d}$ of experimental treatment grouped by those animals which received saline or PG at CIDR insertion.

treated with PG at CIDR insertion had lower progesterone levels than those that received saline at CIDR insertion at 1 and $5 \mathrm{~d}$ following treatment initiation $(\mathrm{P}<0.05)$. Therefore, the DF of cows treated with PG at CIDR insertion developed in the face of lower progesterone levels than the DF of cows treated with saline. All cows had low serum progesterone levels at the time of CIDR removal and estrus due to the PG administered prior to CIDR removal. 


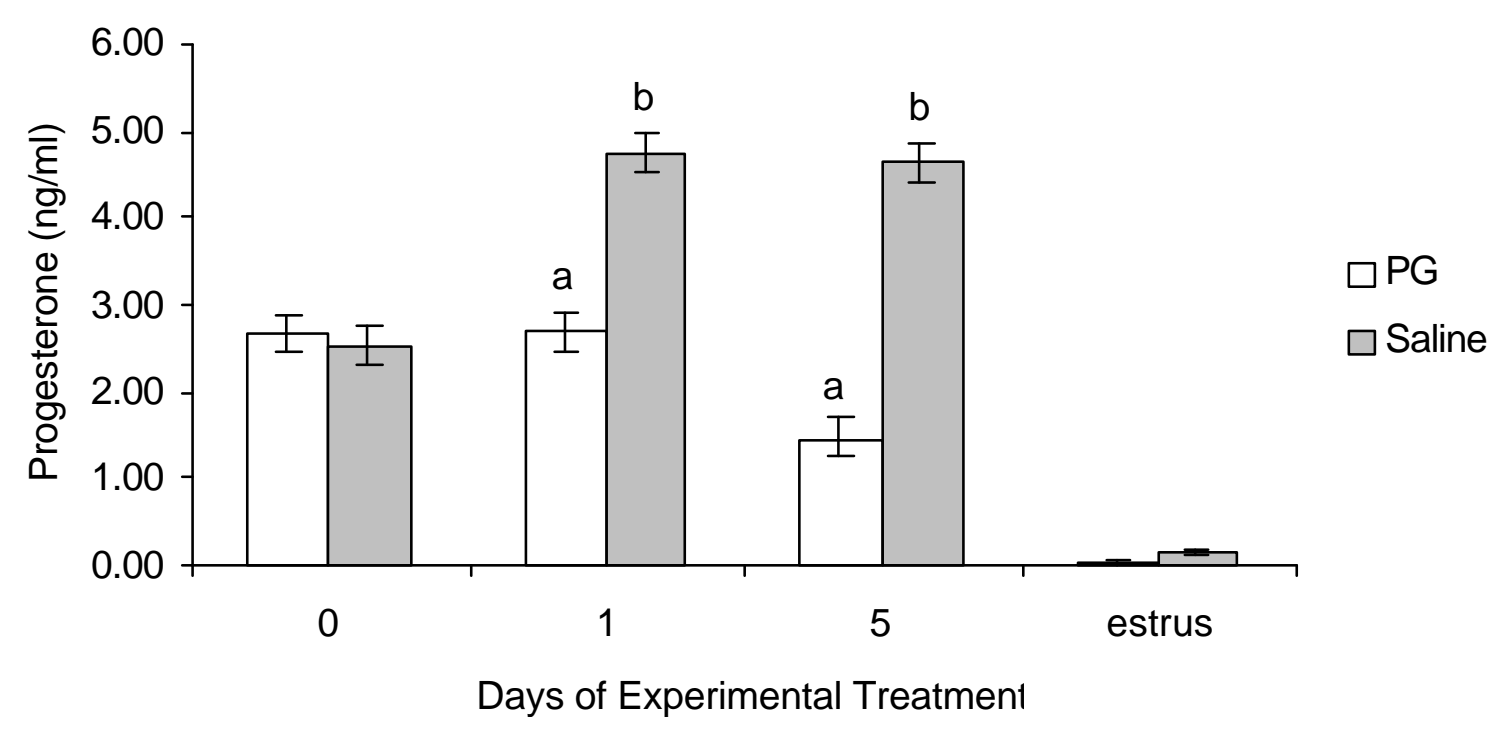

Figure 5.8. Serum progesterone concentrations $(\mathrm{LSM} \pm \mathrm{SE})$ of cows treated with saline or PG at CIDR insertion for 0,1 , and $5 \mathrm{~d}$ following initiation of experimental treatments and at estrus. ${ }^{\mathrm{a}, \mathrm{b}} \mathrm{LSM}$ within day differ $(\mathrm{P}<0.05)$. 


\section{Chapter 6. Discussion}

The purpose of this experiment was to create differences in the interval from induced follicular emergence to the end of a progestin-based estrus synchronization treatment and to examine its effect on growth of the dominant (ovulatory) follicle and the synchrony of estrus. We hypothesized that increasing the interval from emergence to the end of treatment would lead to a larger DF at the time of CIDR removal and that could potentially result in a "tighter" synchrony of estrus. By altering the time of follicle emergence, the duration of progestin treatment, and by varying the progesterone environment in which the DF developed, we successfully created differences in size of the DF at the end of the treatment period.

The treatment that altered follicular dynamics most was the administration of saline or PG at the time of CIDR insertion. Corpora lutea of cows that received PG at CIDR insertion regressed and serum progesterone levels declined. Animals that received saline at CIDR insertion maintained the primary corpus luteum until a luteolytic dose of PG was administered $1 \mathrm{~d}$ prior to CIDR removal. Regression of corpora lutea of cows that received $\mathrm{PG}$ at CIDR insertion resulted in lower progesterone concentrations during the first five days of CIDR treatment compared to those that maintained corpora lutea. Lowered plasma progesterone from regression of the primary CL affected both the growth rate of the DF and the size of the DF at CIDR removal, estrus, and ovulation. We hypothesized that cows which developed a secondary CL from GnRH administration would have resulted in higher circulating progesterone concentrations by five days following CIDR insertion than cows which received $\mathrm{E}_{2}+\mathrm{P}_{4}$; however, administration of GnRH did not significantly increase serum progesterone.

Growth rate of the DF was calculated from daily observations during the period from emergence to estrus. The growth rate of the DF was lower in cows that maintained the primary CL during the first $5 \mathrm{~d}$ of CIDR treatment compared to those in which the CL regressed (1.2 and $1.5 \mathrm{~mm} / \mathrm{d}$, respectively). The increased growth rate of the DF of cows that did not maintain the primary CL throughout CIDR treatment was likely due to the subluteal levels of progesterone during the time the DF developed. Numerous researchers have reported the DF reached a larger diameter under subluteal progesterone 
concentrations compared to those treated with higher levels of progesterone (Savio et al., 1993; Sirois and Fortune, 1990). The larger maximum diameter of the DF, which developed under subluteal levels of progesterone, was most likely due to an increased growth rate of the DF caused by increased LH pulse frequency. Researchers have reported an increased pulse frequency of LH when circulating progesterone levels were experimentally maintained at subluteal levels (Ireland and Roche, 1982; Roberson et al., 1989).

The increased growth rate of the DF observed in this experiment was similar to the pattern of follicular growth that occurs during the stage of the estrous cycle when the $\mathrm{CL}$ is forming or the stage of the cycle when the CL is regressing. During CL formation or early luteal phase, progesterone levels are low because the CL has not reached full maturity. In contrast during the late luteal phase, progesterone levels fall due to regression of the CL. Luteinizing hormone pulse frequency is affected by periods of low circulating progesterone levels. Rahe et al. (1980) reported high LH pulse frequency during the early luteal compared to the mid luteal period. It is during the early luteal phase, when progesterone levels are relatively low, that majority of growth of the anovulatory DF occurs. In contrast, development of the ovulatory DF occurs mostly during the mid-luteal period when progesterone levels are relatively high. Ginther et al. (1989) reported the growth rate of the anovulatory DF was higher $(1.8 \mathrm{~mm} / \mathrm{d})$ then the growth rate of the ovulatory DF $(1.2 \mathrm{~mm} / \mathrm{d})$. Therefore, the increased growth rate of the $\mathrm{DF}$, in cows in which the primary CL regressed, could have been attributed to increased LH pulse frequency associated with lower plasma progesterone concentrations similar to that of the anovulatory DF during the natural estrous cycle.

Duration of CIDR treatment also affected growth rate of the DF. The growth rate of the DF of cows treated with a CIDR for $9 \mathrm{~d}$ was lower than that of cows treated with a CIDR for $7 \mathrm{~d}$ (Table 3). This could have been attributed to the stage of growth of the DF at the time of CIDR removal illustrated by the theoretical growth curve of the DF during the interval from emergence to CIDR removal in Figure 6.1. As the DF reached its maximum size its growth rate may have decreased. The DF of cows treated with a CIDR for $9 \mathrm{~d}$ may have been nearing the end of its growth curve at the time of CIDR removal. 
In contrast, the DF of cows that received a CIDR for $7 \mathrm{~d}$ was still at the mid-growth phase at the time of CIDR removal. Similarly, the growth rate of the DF of cows treated

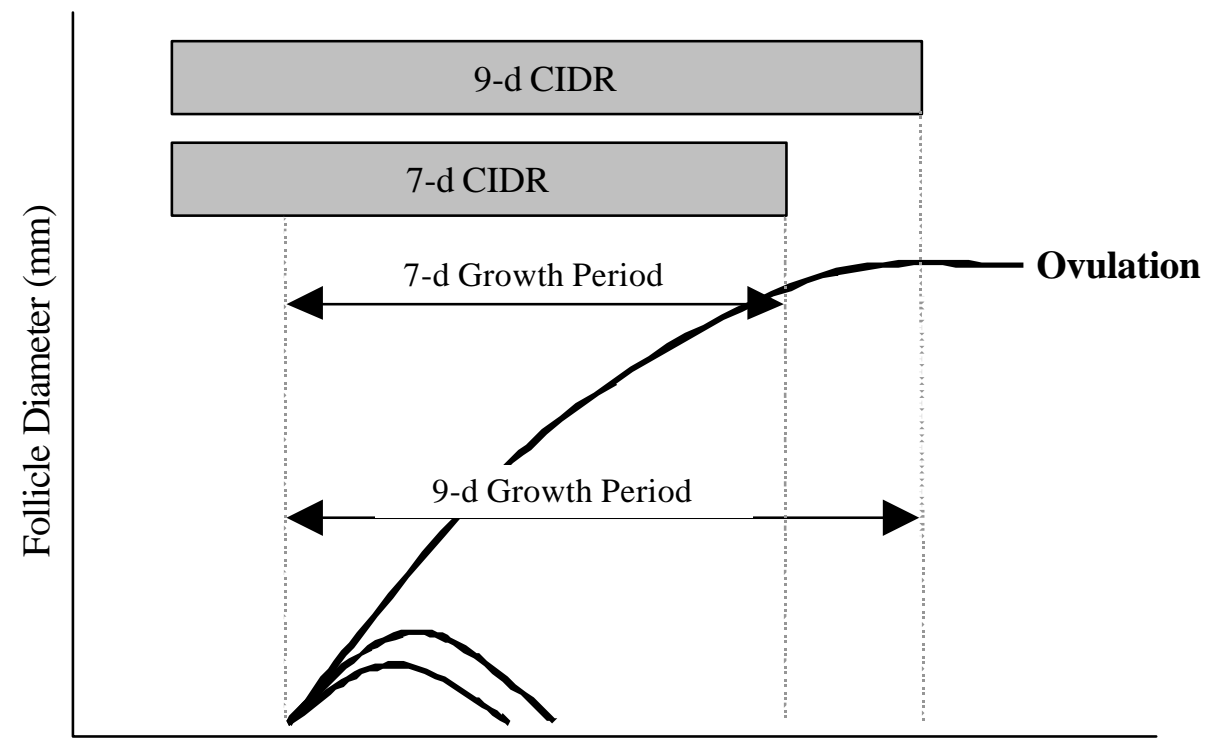

Figure 6.1. A theoretical representation of the growth curve of the DF during the interval from follicular wave emergence to CIDR removal for cows treated with a CIDR for 7 or $9 \mathrm{~d}$.

with $\mathrm{GnRH}$ tended to be lower than that of cows treated with $\mathrm{E}_{2}+\mathrm{P}_{4}$ (Table 3). Due to an earlier time of emergence relative to $\mathrm{GnRH}$ or $\mathrm{E}_{2}+\mathrm{P}_{4}$ treatment, the $\mathrm{DF}$ of cows treated with GnRH may have neared the end of the follicle growth curve similar to cows treated with a CIDR for $9 \mathrm{~d}$. Therefore, the overall growth rate of the DF of cows treated with GnRH or with a CIDR for $9 \mathrm{~d}$ was lower possibly due to a lower DF growth rate near the time of CIDR removal which decreased the overall growth rate from emergence to CIDR removal.

Differences in growth rate of the DF created differences in size of the DF at CIDR removal. The absence or presence of the primary CL affected the growth rate of the DF and the size of the DF at CIDR removal. The DF of cows that had the primary CL regressed was larger than those of cows that maintained the primary CL. The difference in size of the DF was most likely caused by the increased growth rate associated with low progesterone concentrations in animals in which the primary CL regressed due to administration of PG at the time of CIDR insertion. Effects of the low progesterone 
levels were probably due to a resulting higher LH pulse frequency. The size of the DF at estrus and ovulation was also greater for cows in which the primary CL regressed. The size difference in the DF at the time of estrus or ovulation was due to the difference that existed at the time of CIDR removal, not to a difference in the growth from the time of CIDR removal until estrus or ovulation.

In addition to the absence or presence of the primary CL, the administration of $\mathrm{E}_{2}+\mathrm{P}_{4}$ or GnRH significantly affected size of the DF at CIDR removal, at estrus, and at ovulation. The dominant follicles of cows treated with $\mathrm{GnRH}$ were significantly larger at CIDR removal, estrus and ovulation than those of cows treated with $\mathrm{E}_{2}+\mathrm{P}_{4}$. The greater size of the DF at estrus and ovulation associated with GnRH treatment was due to the increased interval from follicle emergence to CIDR removal. Emergence of the ovulatory follicular wave occurred approximately $1.9 \mathrm{~d}$ sooner in cows treated with $\mathrm{GnRH}$ at CIDR insertion than in those treated with $\mathrm{E}_{2}+\mathrm{P}_{4}$. Therefore, the DF of cows treated with GnRH had a longer period to develop prior to CIDR removal. The longer period of growth resulted in a larger DF at CIDR removal. Duration of CIDR treatment affected the interval from follicular wave emergence to CIDR removal thus altering the size of the DF at CIDR removal. Because cows treated with a CIDR for $9 \mathrm{~d}$ had $2 \mathrm{~d}$ longer to develop prior to CIDR removal than those treated with a 7-d CIDR, those treated with a 9-d CIDR tended to have a larger DF at CIDR removal.

An unexpected finding was the greater variation in the interval from treatment to follicular wave emergence among cows treated with $\mathrm{E}_{2}+\mathrm{P}_{4}$ in contrast to the more consistent interval from treatment to emergence in those treated with GnRH. This finding is the opposite of what Martinez et al. (1997) reported after comparing $\mathrm{E}_{2}+\mathrm{P}_{4}$ with $\mathrm{GnRH}$ treatment. They reported the range in the interval from $\mathrm{E}_{2}+\mathrm{P}_{4}$ treatment to follicular wave emergence was 3 to $4 \mathrm{~d}$; however, in the current study, the range in the interval from $\mathrm{E}_{2}+\mathrm{P}_{4}$ treatment to wave emergence was 1 to $7 \mathrm{~d}$. Similarly, the range in the interval from $\mathrm{GnRH}$ treatment to wave emergence was less in the current study ( 0 to 2 d) than in the GnRH-treated group (-1 to 5 d) of the experiment conducted by Martinez et al. (1997).

Altering the time of follicle emergence and duration of CIDR treatment created differences in the interval from DF emergence to CIDR withdrawal that resulted in 
differences in size of the DF at CIDR removal, at estrus, and at ovulation. The interval from emergence to CIDR removal was $2 \mathrm{~d}$ shorter in cows that received $\mathrm{E}_{2}+\mathrm{P}_{4}$ or a 7-d CIDR treatment duration than those that received GnRH or a 9-d CIDR treatment, respectively. Combining the effects of the duration of CIDR treatment and the treatment used to cause follicular wave emergence manifested the differences in the interval from emergence to CIDR removal. Consider, for example, the interval from emergence to CIDR removal in cows treated with $\mathrm{E}_{2}+\mathrm{P}_{4}$ that received a 7-d CIDR treatment. Those cows had an interval from emergence to CIDR removal of approximately $3.7 \mathrm{~d}$, much shorter than the 8.6-d interval recorded in cows treated with GnRH and a 9-d CIDR. Cows in the later group had approximately $4.9 \mathrm{~d}$ longer to develop a DF prior to CIDR removal. Consequently, they had a larger DF at CIDR removal, at estrus, and at ovulation. Because we were so successful in altering the size of the DF among groups in this experiment, we hypothesized that those differences in size of the DF at CIDR removal would lead to differences in the interval from CIDR removal to estrus and the synchrony of estrus.

The only significant effect on the interval from CIDR removal to estrus was the absence or presence of the primary CL during the treatment with a CIDR. Cows treated with saline at CIDR insertion, that maintained the primary CL, had a smaller DF at CIDR removal and took longer following CIDR removal to exhibit estrus than those in which the primary CL had regressed. Although the timing of estrus was not significantly influenced by other treatments, cows treated with $\mathrm{E}_{2}+\mathrm{P}_{4}$ or that received a $7-\mathrm{d}$ CIDR treatment tended to have a longer interval from CIDR removal to the onset of estrus. The tendency for a longer interval from CIDR removal to estrus, in cows treated with $\mathrm{E}_{2}+\mathrm{P}_{4}$ or a 7-d CIDR treatment, was most likely due to a smaller DF that was present at CIDR removal in those groups. This relationship was supported by the regression of the interval from CIDR removal to estrus on the size of the DF at CIDR removal (Figure 9). Cows with a smaller DF at CIDR removal required a longer time to exhibit estrus. If larger follicles secreted more estrogen (Sirois and Fortune, 1990), it follows that the smaller DF present at CIDR removal required a longer period of growth to reach a level of estrogen production necessary for the animal to exhibit behavioral estrus. Conversely, 
animals with a larger DF present at CIDR removal reached estrus sooner because of greater estrogen secretion by those follicles.

The experimental treatments administered in this experiment created differences in the size of the DF that influenced the timing of estrus, but differences in follicle size did not affect the synchrony of estrus among animals in the treatment groups. Synchrony of estrus was defined as the variation around the mean interval from CIDR removal to estrus. No differences in variance were found among different treatments. This was surprising, considering the differences in DF size created by experimental treatments. The hypothesis, that a larger DF at CIDR removal and shorter interval from CIDR removal to estrus, would increase the synchrony of estrus was not supported. Lane et al. (2001) also reported no improvement in synchrony of estrus by creating a longer interval from DF emergence to progestin removal. In that experiment, heifers on d 2, 5, 10 or 13 of the estrous cycle were fitted with a PRID for $8 \mathrm{~d}$ and received an injection of GnRH or estradiol benzoate at PRID insertion or were fitted with a PRID for $10 \mathrm{~d}$ and received estradiol benzoate at PRID insertion. Heifers fitted with PRIDs for $8 \mathrm{~d}$ also received an injection of PG $1 \mathrm{~d}$ prior to PRID removal. Heifers that received the PRID for $10 \mathrm{~d}$ did not receive an injection of $\mathrm{PG}$, and will not be used for comparison. Comparing the two 8-d PRID treatments across the four different days of the cycle, the interval from follicle emergence to PRID removal, would have been expected to be longest in heifers that received GnRH at PRID insertion due to an earlier time of follicular wave emergence relative to treatment compared to those that received estradiol benzoate. If the hypothesized relationship between a longer interval from follicle emergence to progestin removal and tighter synchrony of estrus existed, heifers that received GnRH at PRID insertion should have been synchronized more closely. However, the synchrony of estrus was not different between the two 8-d PRID treatment groups when data were combined across $\mathrm{d} 2,5,10$, and 13 of the estrous cycle when treatments were initiated.

Garcia and Salaheddine (2001) reported no difference in the synchrony of estrus resulting from differing intervals from emergence of a new follicular wave to progestin removal. Heifers were treated with a progestin implant (Crestar) or a CIDR for $9 \mathrm{~d}$. Heifers that received the Crestar treatment were administered an estrogen (estradiol-17 beta or valerate) at Crestar insertion or two days following Crestar insertion. Animals 
that received a CIDR were administered estradiol-17 beta $2 \mathrm{~d}$ following CIDR insertion. By administering estradiol at progestin insertion or $2 \mathrm{~d}$ following insertion, the interval from DF emergence to progestin removal was altered by approximately $2 \mathrm{~d}$. Thus, cows administered estrogen $2 \mathrm{~d}$ following the start of the progestin treatment, would have had a shorter interval from follicular wave emergence to progestin withdrawal, in turn leading to a smaller DF at progestin withdrawal. Although size of the DF at progestin removal was not assessed in that experiment, no significant differences were created in the size of the DF at ovulation or the synchrony of estrus. The experimental treatment groups of Garcia and Salaheddine (2001) evoked changes in the interval from follicular wave emergence to progestin removal comparable to groups that received $\mathrm{E}_{2}+\mathrm{P}_{4}$ at $\mathrm{CIDR}$ insertion and a CIDR treatment duration of 7 or $9 \mathrm{~d}$ in the current experiment. In the current experiment, those treatments altered the interval from emergence to progestin removal by $2 \mathrm{~d}$ and affected the size of the DF at CIDR removal, but did not affect the synchrony of estrus. Similar treatments in the experiment performed by Garcia and Salaheddine (2001) did not influence DF size or the synchrony of estrus; however, the number of animals per treatment group $(n=5)$ in their experiment was smaller than that of the current experiment though. Therefore, data from the Garcia and Salaheddine (2001) experiment may not have reflected the effect of differing intervals from emergence to progestin withdrawal on follicular dynamics. Based on previous research and the results from the current experiment it appears that increasing the size of the DF by lengthening the interval from emergence to progestin withdrawal may affect the timing of estrus following treatment, but it does not increase the synchrony of estrus.

Conception rate from synchronized estrus was not investigated in groups of cows used in this experiment; however, some of the experimental treatments might have led to reduced fertility resulting from prolonged dominance of the DF. The combination of administration of GnRH and a 9-d CIDR treatment yielded the longest interval from follicular wave emergence to CIDR withdrawal in this experiment, 7.6 d. The duration of dominance of the DF in cows treated with GnRH and a 9-d CIDR treatment was approximately $6.4 \mathrm{~d}$. The duration of dominance is defined as the period from deviation of the DF to the onset of estrus. Based on the results of Austin et al. (1999), the duration of dominance of the DF in cows treated with GnRH and a 9-d CIDR in the current 
experiment may not have been detrimental to fertility. Austin et al. (1999) reported when the duration of dominance was extended to $10.4 \mathrm{~d}$, there was a significant reduction in pregnancy rate compared to dominant follicles which had a 2.1-d duration of dominance (Table 6.1). Pregnancy rates though associated with the DF of cows that exhibited a duration of dominance from 4.9 to $10.4 \mathrm{~d}$ were not different. Therefore, the exact duration of dominance of the DF, which results in reduced fertility, is difficult to pinpoint.

Table 6.1. The effect of the duration of dominance of the ovulatory follicle on fertility in heifers. Adapted from Austin et al. (1999).

\begin{tabular}{ccc}
\hline Duration of dominance $(\mathrm{d})^{*}$ & No. of heifers & Pregnancy rate $(\%)$ \\
\hline $2.1 \pm 0.3$ & 9 & $89^{\mathrm{a}}$ \\
$4.9 \pm 0.1$ & 28 & $68^{\mathrm{a}, \mathrm{b}}$ \\
$6.6 \pm 0.2$ & 18 & $78^{\mathrm{a}, \mathrm{b}}$ \\
$8.3 \pm 0.1$ & 48 & $71^{\mathrm{a}, \mathrm{b}}$ \\
$10.4 \pm 0.1$ & 23 & $52^{\mathrm{b}}$ \\
$12.0 \pm 0.1$ & 17 & $12^{\mathrm{c}}$ \\
${ }^{*}$ Means \pm SE \\
a,b,c Means with uncommon superscripts differ significantly $(\mathrm{P}<0.05)$
\end{tabular}

Characteristics of the estrus period were recorded from the HeatWatch system. The duration of estrus was not different between experimental treatments. The mean duration of estrus for cows across all treatments was $15.3 \pm 0.63 \mathrm{~h}$. The mean number of standing events, independent of the length of estrus, during estrus was significantly greater in cows treated with $\mathrm{GnRH}(43.7)$ than among those treated with $\mathrm{E}_{2}+\mathrm{P}_{4}(28.1)$ independent of the length of estrus. It would be tempting to say that the increased number of standing events associated with cows treated with GnRH could be due to a larger follicle at estrus. Cows, in which the primary CL regressed during treatment, had a numerically higher number of standing events (38.7) than those, which maintained the primary CL (33.1); however, that difference was not statistically significant. Cows that maintained the primary CL also had a larger DF at estrus than those in which the primary CL regressed. A larger DF, associated with cows that received $\mathrm{GnRH}$ or in which the 
primary CL regressed, could have secreted more estrogen and which resulted in the tendency for an increased intensity of estrus. Sirois and Fortune (1990) reported increased circulating levels of estradiol-17 beta in heifers that developed large, persistent follicles during a 14-d, single CIDR treatment compared to untreated controls in which the DF was smaller in size. However, cows that received a CIDR for $9 \mathrm{~d}$ had a larger DF at estrus, and although not statistically significant, appeared to have exhibited a fewer number of standing events than those that received a CIDR for $7 \mathrm{~d}$ which had a smaller DF at estrus. Therefore, the claim that a larger DF at estrus led to an increased intensity of estrus maybe hard to substantiate based on data from the current experiment.

The duration of estrus in the current experiment, $15.3 \pm 0.63 \mathrm{~h}$, was similar to that reported by Stevenson et al. (1996) who also utilized the HeatWatch system. In their experiment, the duration of estrus in 39 estrus-synchronized, crossbred beef heifers averaged $14 \pm 0.8 \mathrm{~h}$ and ranged from 2.6 to $26.2 \mathrm{~h}$. However, Rorie et al. (2001) reported a shorter duration of estrus in 364 estrus-synchronized, Angus cows $(10.1 \pm 0.3 \mathrm{~h})$ than that of the current experiment. Similarly, Rae et al. (1998) reported a shorter duration of estrus in 29 estrus-synchronized Angus heifers $(8.52 \pm 1.20)$ compared to that of the current experiment.

The mean number of standing events, during the estrus period (intensity of estrus) in the current experiment, across all treatments, was $36.5 \pm 2.89$. This was similar to results reported by Rorie et al. (2001) $(35.1 \pm 1.7)$. However, Stevenson et al. (1996) reported an overall higher number of standing events $(50.1 \pm 6.4)$ than the current study. The greater number of standing events associated with their experiment compared to the current experiment maybe due to the age of animals used in the experiment. Stevenson et al. (1996) used yearling beef heifers as adverse to mature, Angus cows which were used in the current experiment.

The interval from estrus to ovulation was not different across all treatments in this experiment. This indicates that ovulation is an event that is fairly consistent relative to the timing of the onset of estrus. The average interval $( \pm \mathrm{SD})$ from estrus to ovulation for all cows, $32.0 \pm 4.4 \mathrm{~h}$, was similar to that recorded by Sirolli (unpublished data) for estrus-synchronized beef cows $(31.1 \pm 3.0 \mathrm{~h})$. The only comparison to the current study for the time of ovulation relative to the onset of estrus (determined by HeatWatch) is the 
work of Walker et al. (1996). In their experiment, ultrasound examinations of ovarian structures were performed every $2 \mathrm{~h}$ commencing $24 \mathrm{~h}$ after the onset of estrus to determine the time of ovulation. They reported the ovulation time, relative to the onset of estrus, from the combined data from cows which exhibited synchronized and spontaneous estrus, to be $27.6 \pm 5.4 \mathrm{~h}$. Although the pre-ovulatory LH surge was not assessed in either experiment, it seems unlikely that a later time of ovulation in beef cattle was related to a longer interval from the LH surge to ovulation. More likely, the difference in the time of ovulation relative to the time of the onset of estrus may have been caused by an earlier expression of behavioral estrus in beef cattle used in this experiment. 


\section{Chapter 7. Implications}

The results of this experiment suggest that differences in the size of the DF caused by length of progestin treatment, differing times of follicle emergence from $\mathrm{GnRH}$ or $\mathrm{E}_{2}+\mathrm{P}_{4}$ treatment, and differing progesterone environments do not affect synchrony of estrus. Therefore, decreasing the length of progestin treatment, irrespective of using estrogen or GnRH to control follicular wave emergence, will yield an acceptable synchrony of estrus. In addition, if animals begin treatment during the follicular phase of the estrous cycle or luteolysis occurs during progestin treatment, differing levels of circulating progesterone will not effect the synchrony of estrus. In conclusion, differences in follicular growth and development may be created by different short-term, progestin-based estrus synchronization systems, but these differences will not drastically affect the synchrony of estrus. 


\section{Literature Cited}

Adams, G. P., K. Kot, C. A. Smith, and O. J. Ginther. 1993. Selection of the dominant follicle and suppression of follicular growth in heifers. Anim. Reprod.

Sci.30:259-271.

Allen, E., and E. A. Doisy. 1923. An ovarian hormone. Preliminary report on its localization, extraction and partial purification, and action in test animals. J. Amer. Med. Assoc. 81:819-821.

Austin, E. J., M. Mihm, M. P. Ryan, D. H. Williams, and J. F. Roche. 1999. Effect of duration of dominance of the ovulatory follicle on onset of estrus and fertility in heifers. J. Anim. Sci. 77:3329-26.

Barnes, M. A., G. W. Kazmer, and S. T. Bierly. 1981. Gonadotropic and ovarian hormone response in dairy cows treated with norgestomet and estradiol valerate. Theriogenology. 16:13-25.

Beg, M. A., D. R. Bergfelt, K. Kot, M. C. Wiltbank, and O. J. Ginther. 2001. Follicularfluid factors and granulosa-cell gene expression associated with follicle deviation in cattle. Biol. Reprod. 64:432-441.

Bentley, D., M. Martinez, B. Mitchell, and T. Carruthers. 1998. LH release, dominant follicle response and wave emergence: the effect of three commercial GnRH products. Theriogenology. 49:338 (abstr.).

Bigelow, K. L. and J. E. Fortune. 1998. Characteristics of prolonged dominant versus control follicles: follicle cell numbers, steroidogenic capabilities, and messenger ribonucleic acid for steroidogenic enzymes. Biol. Reprod. 58:1241-9.

Bo, G. A., G. P. Adams, L. F. Nasser, R. A. Pierson, and R. J. Mapletoft. 1993. Effect of estradiol valerate on ovarian follicles, emergence of follicular waves and circulating gonadotropins in heifers. Theriogenology. 40:22-239.

Bo, G. A., G. P. Adams, R. A. Pierson, H. E. Tribulo, M. Caccia, and R. J. Mapletoft. 1994. Follicular wave dynamics after estradiol-17 beta treatment of heifers with or without a progestogen implant. Theriogenology. 41:1555-1569.

Bo, G. A., D. R. Bergfelt, G. M. Brogliatti, R. A. Pierson, G. P. Adams, and R. J. Mapletoft. 2000. Local versus systemic effects of exogenous estradiol-17 beta on ovarian follicular dynamics in heifers with progestogen implants. Anim. Reprod. Sci. 59:141-157.

Borchert, K. M., C. E. Farin, and S. P. Washburn. 1999. Effect of estrus synchronization with norgestomet on the integrity of oocytes from persistent follicles in beef cattle. J. Anim. Sci. 77:2742-48. 
Bridges, P. J., P. E. Lewis, W. R. Wagner, and E. K. Inskeep. 1999. Follicular growth, estrus and pregnancy after fixed-time insemination in beef cows treated with intravaginal progesterone inserts and estradiol benzoate. Theriogenology. 52:573-583.

Brink, J. T., and G. H. Kiracofe. 1987. Effect of estrous cycle stage at Synchro-Mate B treatment on conception and time to estrus in cattle. Theriogenology. 21:513518.

Christian, R. E., and L. E. Casida. 1948. The effect of progesterone in altering the estrus cycle of the cow. J. Anim. Sci. 7:540 (Abstr.).

Corner, G. W., and W. M. Allen. 1929. Physiology of the corpus luteum II. Production of a special uterine reaction (progestational proliferation) by extracts of the corpus luteum. Amer. J. Physiol. 88:326-339.

Dominko, T. and N. L. First. 1997. Timing of meiotic progression in bovine oocytes and its effect on early embryo development. Mol. Reprod. Develop. 47:456-467.

Folman, Y., S. R. McPhee, and L. A. Cummin. 1981. The effect of "estrumate" followed by progesterone coils on oestrus synchronization and conception of postpartum beef and dairy cows. Anim. Reprod. Sci. 4:117-126.

Fortune, J. E., J. Sirois, and S. M. Quirk. 1988. The growth and differentiation of ovarian follicles during the bovine estrous cycle. Theriogenology. 29:95-109.

Garcia, A. and M. Salaheddine. 2001. Effect of estrus synchronization with estradiol-17 beta and progesterone on follicular wave dynamics in dairy heifers. Reprod. Dom. Anim. 36:301-307.

Ginther, O. J., J. P. Kastelic, and L. Knopf. 1989. Composition and characteristics of follicular waves during the bovine estrous cycle. Anim. Reprod. Sci. 20:187200.

Ginther, O. J., M. C. Wiltbank, P. M. Fricke, J. R. Gibbons, and K. Kot. 1996. Selection of the dominant follicle in cattle. Biol. Reprod. 55:1187-94.

Ginther, O. J. 1998. Ultrasonic imaging and animal reproduction: cattle. Equiservices Publishing. Cross Plains, WI.

Ginther, O. J., D. R. Bergfelt, M. A. Beg, and K. Kot. 2001. Follicle selection in cattle: relationships among growth rate, diameter ranking, and capacity for dominance. Biol. Reprod. 65:345-350.

Ginther, O. J., M. A. Beg, D. R. Bergfelt, F. X. Donadeu, and K. Kot. 2001b. Follicle selection in monovular species. J. Reprod. Fert. 65:638-647. 
Hansel, W., P. V. Malven, and D. L. Black. 1961. Estrous cycle regulation in the bovine. J. Anim. Sci. 20:621-625.

Holt, L. C., W. D. Whittier, F. C. Gwazdauskas, and W. E. Vinson. 1989. Early postpartum reproductive profiles in Holstein cows with retained placenta and uterine discharges. J. Dairy Sci. 72:533-539.

Humphrey, W. D., L. D. Hopper, P. Clemente, T. G. Dunn, and C. C. Kaltenbach. 1977. Estrus and conception in heifers treated with norgestomet and estradiol valerate vs norgestamet alone. In: Proc. Western Section, Am. Soc. of Anim. Sci. p.173-4.

Ireland, J. J., and J. F. Roche. 1982. Effect of progesterone on basal LH and episodic LH and FSH secretion in heifers. J. Reprod. Fertil. 64:295-302.

Kesler, D. J., D. B. Faulkner, R. B. Shirley, T. S. Tyson, F. A. Ireland, and R. S. Ott. 1996. Effect of interval from melengestrol acetate to prostaglandin F2 alpha on timed and synchronized pregnancy rates of beef heifers and cows. J. Anim. Sci. $74: 2885-90$.

Kittok, R. J., J. H. Britt, and E. J. Convey. 1973. Endocrine response after GnRH in luteal phase cows and cows with follicular cysts. J. Anim. Sci. 37:985-989

Knopf, L., J. P. Kastelic, E. Schallenberger, and O. J. Ginther. 1989. Ovarian follicular dynamics in heifers: test of two-wave hypothesis by ultrasonically monitoring individual follicles. Dom. Anim. Endocrinol. 6:111-119.

Lamb, G. C., D. W. Nix, J. S. Stevenson, and L. R. Corah. 2000. Prolonging the MGAprostaglandin F2 alpha interval from 17 to 19 days in an estrous synchronization system for heifers. Theriogenology. 53:691-8.

Lammoglia, M. A., R. E. Short, S. E. Bellows, R. A. Bellows, M. D. MacNeil, and H. D. Hafs. 1998. Induced and synchronized estrus in cattle: dose titration of estradiol benzoate in peripubertal heifers and postpartum cows after treatment with an intravaginal progesterone releasing insert and prostaglandin F2-alpha. J. Anim. Sci. 76:1662-70.

Lane, E. A., E. J. Austin, J. F. Roche, and M. A. Crowe. 2001. The effect of estradiol benzoate or a synthetic gonadotropin releasing hormone used at the start of a progesterone treatment on estrous repsonse in cattle. Theriogenology. 56:79-90.

Macmillan, K. L. and W. W. Thatcher. 1991. Effects of an agonist of gonadotropinreleasing hormone on ovarian follicles in cattle. Bio. Reprod. 45:883-889.

Macmillan, K. L. and A. J. Peterson. 1993. A new intravaginal progesterone releasing device for cattle (CIDR-B) for oestrous synchronization, increasing pregnancy rates and the treatment of post-partum anoestrus. Anim. Reprod. Sci. 33:1-25. 
Makepeace, A. W., G. L. Weinstein, and M. H. Friedman. 1937. The effect of progestin and progesterone on ovulation in the rabbit. Am J Physiol 119:512-516.

Martinez, M. F., D. R. Bergfelt, G. P. Adams, J. P. Kastelic, and R. J. Mapletoft. 1997. Synchronization of follicular wave emergence and its use in an estrus synchronization program. Theriogenology. 47:145(abstr.).

Mihm, M., N. Curran, P. Hyttel, P. G. Knight, M. P. Boland, and J. F. Roche. 1999. Effect of dominant follicle persistence on follicular fluid oestradiol and inhibin and on oocyte maturation in heifers. J. Reprod. Fertil. 116:293-304.

Moffatt, R. J., W. G. Zollers, Jr., W. V. Welshons, K. R. Kieborz, H. A. Garverick, and M. F. Smith. 1993. Basis of norgestomet action as a progestin in cattle. Dom. Anim. Reprod. 20:21-30.

Moreira, F., R.L. de la Sota, T. Diaz, and W.W. Thatcher. 2000. Effect of day of the estrous cycle at the initiation of a timed artificial insemination protocol on reproductive responses in dairy heifers. J. Anim. Sci. 78:1568-76

Noble, K.M., J.E. Tebble, D. Harvey, and H. Dobson. 2000. Ultrasonography and hormone profiles of persistent ovarian follicles (cysts) induced with low does of progesterone in cattle. J. Reprod. Fertil. 120:361-366.

Odde, K. J. 1990. A review of synchronization of estrus in postpartum cattle. J. Anim. Sci. 68:817-830.

Patterson, D. J., G. H. Kiracofe, J. S. Stevenson, and L. R. Corah. 1989. Control of the bovine estrous cycle with melengestrol acetate (MGA): a review. J. Anim. Sci. 67:1895-1906.

Patterson, D. J, J. B. Hall, N. W. Bradley, K. K. Schillo, B. L. Woods, and J. M. Kearnan. 1995. Improved synchrony, conception rate, and fecundity in postpartum suckled beef cows fed melengestrol acetate prior to prostaglandin F2-alpha. J. Anim. Sci. 73:954-959.

Pierson, R.A. and O. J. Ginther. 1984. Ultrasonography of the bovine ovary. Theriogenology. 21:495-504.

Pierson, R. A. and O. J. Ginther. 1987. Follicular populations during the estrous cycle in heifers: I. Influence of day. Anim. Reprod. Sci. 14:165-176.

Pratt, S. L., J. C. Spitzer, G. L. Burns, and B. B. Plyler. 1991. Luteal function, estrous response, and pregnancy rate after treatment with norgestomet and various dosages of estradiol valerate in suckled cows. J. Anim. Sci. 69:2721-2726. 
Price, C. A. and R. Webb. 1988. Steroid control of gonadotropin secretion and ovarian function in heifers. Endocrinology. 122:2222-31

Pursley, J. R., M. O. Mee, and M. C. Wiltbank. 1995. Synchronization of ovulation in dairy cows using PGF2-alpha and GnRH. Theriogenology. 44:915 (abstr.)

Pursley, J. R., M. C. Wiltbank, J. S. Stevenson, J. S. Ottobre, H. A. Gaverick, and L. L. Anderson. 1997. Pregnancy rates per artificial insemination for cows and heifers inseminated at a synchronized ovulation or synchronized estrus. J. Dairy Sci. 80:295-300.

Rae, D. O., P. J. Chenoweth, M. A. Giangreco, P. W. Dixon, and F. L. Bennett. 1999. Assessment of estrus detection by visual observation and electronic detection methods and characterization of factors associated with estrus and pregnancy in beef heifers. Theriogenology. 51:1121-1132.

Rahe, C. H., R. E. Owens, J. L. Fleeger, H. J. Newton, and P. G. Harms. 1980. Pattern of plasma luteinizing hormone in the cyclic cow: dependence upon the period of the cycle. Endocrinology. 107:498-503.

Rajakoski, E. 1960. The ovarian follicular system in sexually mature heifers with special reference to seasonal, cyclical, and left-right variations. ACTA Endocrinol. 34:7-68.

Revah, I. And W.R. Butler. 1996. Prolonged dominance of follicles and reduced viability of bovine oocytes. J. Reprod. Fertil. 106:39-47.

Roberson. M. S., M. W. Wolfe, T. T. Stumpf, R. J. Kittok, and J. E. Kinder. 1989. Luteinizing hormone secretion and corpus luteum function in cows receiving two levels of progesterone. Biol. Reprod. 41:997-1003.

Roche, J. F. 1974. Effect of short term progesterone treatment on estrous response and fertility in heifers. J. Reprod. Fertil. 40:433-440.

Roche, J. F. 1976. Comparison of pregnancy rate in heifers and suckler cows after progesterone or prostaglandin treatments. Vet Rec. 99:184-186.

Roche, J. F. 1996. Control and regulation of folliculogenesis - a symposium in perspective. Reviews of Reproduction. 1:19-27.

Rorie, R. W., T. R. Bilby, and T. D. Lester. 2002. Application of electronic estrus detection technologies to reproductive management of cattle. Theriogenology. 57:137-148.

SAS. 1999. SAS system for Windows. Version 8. SAS Institute, Inc., Cary NC. 
Savio, J. D., W. W. Thatcher, G. R. Morris, K. Entwistle, M. Drost, and M. R. Mattiacci. 1993. Effects of induction of low plasma progesterone concentrations with a progesterone-releasing intravaginal device on follicular turnover and fertility in cattle. J. Reprod. Fertil. 98:77-84.

Senger, P. L. 1997. Pathways to pregnancy and parturition. Current Conceptions Inc., Pullman, Washington.

Sirois, J. and J. E. Fortune. 1990. Lengthening the bovine estrous cycle with low levels of exogenous progesterone: a model for studying ovarian follicular dominance. Endocrinology. 127:916-925.

Smith, R. D., A. J. Pomerantz, W. E. Beal, J. P. McCann, T. E. Pilbeam, and W. Hansel. 1984. Insemination of Holstein heifers at a preset time after estrous cycle synchronization using progesterone and prostaglandin. J. Anim. Sci. 58:792-800.

Spitzer, J. C., W. C. Burrell, D. G. LeFever, R. W. Whitman, and J. N. Wiltbank. 1978. Synchronization of estrus in beef cattle: I. Utilization of norgestomet implant and injection of estradiol valerate. Theriogenology. 10:181-200.

Steele, R. G. D. and J. H. Torrie. 1960. Principles and procedures of statistics: with special reference to the biological sciences. McGraw Hill, New York, NY.

Stevenson, J. S., M. K. Schmidt, and E. P. Call. 1984. Stage of estrous cycle, time of insemination, and seasonal effects on estrus and fertility of Holstein heifers after prostaglandin F2 alpha. J. Dairy Sci. 67:1798-805.

Stevenson, J. S., M. W. Smith, J. R. Jaeger, L. R. Corah, and D. G. LeFever. 1996. Detection of estrus by visual observation and radiotelemetry in peripubertal, estrus-synchronized beef heifers. J. Anim. Sci. 74:729-735

Stock, A. E. and J. E. Fortune. 1993. Ovarian follicular dominance in cattle: relationship between prolonged growth of the ovulatory follicle and endocrine parameters. Endocrinology. 132:1108-14.

Szollosi, D. 1993. Oocyte Maturation. In: Reproduction in mammals and man. Elllipses, Paris. p. 307-325.

Taft, R., N. Ahmad, and E. K. Inskeep. 1996. Exogenous pulses of luteinizing hormone cause persistence of the largest bovine ovarian follicle. J. Anim. Sci. 74:2985-91.

Ulberg, L. C., and C. E. Lindley. 1960. Use of progesterone and estrogen in the control of reproductive activities in beef cattle. J. Anim. Sci. 19:1132.

Walker, W. L., R. L. Nebel, and M. L. McGilliard. 1996. Time of ovulation relative to mounting activity in dairy cattle. J. Dairy Sci. 79:1555-61. 
Wiltbank, J. N., D. R. Zimmerman, J. E. Ingalls, and W. W. Rowden. 1965. Use of progestational compounds alone or in combination with estrogen for synchronization of estrus. J. Anim. Sci. 24:990-994.

Wiltbank, J.N., J. C. Sturges, D. Wideman, D.G. LeFever, and L.C. Faulkner. 1971. Control of estrus and ovulation using subcutaneous implants and estrogens in beef cattle. J. Anim. Sci. 33:600-606.

Zimbleman, R.G. 1963. Maintenance of pregnancy in heifers with oral progestogens. J. Anim. Sci. 22:868.

Zimbleman, R.G. and L.W. Smith. 1966. Control of ovulation in cattle with melengestrol acetate. J. Reprod. Fert. 11:185-191. 


\section{Vita}

Matthew Douglas Utt, son of Robert Douglas and Georgia Utt, was born July 8, 1978 in Richmond, Virginia. Following graduation from James River High School in June, 1996, he began work towards a Bachelor of Science degree in Animal and Poultry Sciences at Virginia Polytechnic Institute and State University in the fall of that year. He completed the Bachelor of Science degree in July, 2000. Matthew began work on his Master of Science degree in Animal and Poultry Sciences (Physiology of Reproduction) under the direction of Dr. W. E. Beal at Virginia Polytechnic Institute and State University following completion of his Bachelor of Science degree. Matthew is a member of the American Society of Animal Science. 